ARTICLE

\title{
Inhibiting Mycobacterium tuberculosis CoaBC by targeting an allosteric site
}

Vitor Mendes (10 ${ }^{1 凶}$, Simon R. Green ${ }^{2}$, Joanna C. Evans ${ }^{3}$, Jeannine Hess (1D ${ }^{4}$, Michal Blaszczyk ${ }^{1}$ Christina Spry $\mathbb{0}^{4}$, Owain Bryant ${ }^{1}$, James Cory-Wright ${ }^{1}$, Daniel S-H. Chan ${ }^{4}$, Pedro H. M. Torres ${ }^{1}$, Zhe Wang ${ }^{5}$, Navid Nahiyaan ${ }^{5}$, Sandra O'Neill2 ${ }^{2}$ Sebastian Damerow ${ }^{2}$, John Post ${ }^{2}$, Tracy Bayliss ${ }^{2}$, Sasha L. Lynch ${ }^{3}$, Anthony G. Coyne (10) ${ }^{4}$, Peter C. Ray ${ }^{2}$, Chris Abell (1) ${ }^{4}$, Kyu Y. Rhee (i) ${ }^{5}$, Helena I. M. Boshoff (i) ${ }^{6}$, Clifton E. Barry III (D) ${ }^{3,6}$, Valerie Mizrahi ${ }^{3}$, Paul G. Wyatt ${ }^{2} \&{\text { Tom L. Blundell }{ }^{1 \times}}^{1 \times}$

Coenzyme A ( CoA) is a fundamental co-factor for all life, involved in numerous metabolic pathways and cellular processes, and its biosynthetic pathway has raised substantial interest as a drug target against multiple pathogens including Mycobacterium tuberculosis. The biosynthesis of CoA is performed in five steps, with the second and third steps being catalysed in the vast majority of prokaryotes, including $M$. tuberculosis, by a single bifunctional protein, CoaBC. Depletion of CoaBC was found to be bactericidal in M. tuberculosis. Here we report the first structure of a full-length CoaBC, from the model organism Mycobacterium smegmatis, describe how it is organised as a dodecamer and regulated by CoA thioesters. A highthroughput biochemical screen focusing on $\mathrm{CoaB}$ identified two inhibitors with different chemical scaffolds. Hit expansion led to the discovery of potent and selective inhibitors of M. tuberculosis CoaB, which we show to bind to a cryptic allosteric site within CoaB.

\footnotetext{
${ }^{1}$ Department of Biochemistry, University of Cambridge, 80 Tennis Court Road, Cambridge CB2 1GA, UK. ${ }^{2}$ Drug Discovery Unit, College of Life Sciences, University of Dundee, Dow Street, Dundee DD1 5EH Scotland, UK. ${ }^{3}$ MRC/NHLS/UCT Molecular Mycobacteriology Research Unit \& DST/NRF Centre of Excellence for Biomedical TB Research \& Wellcome Centre for Infectious Diseases Research in Africa, Institute of Infectious Disease and Molecular Medicine and Department of Pathology, Faculty of Health Sciences, University of Cape Town, Anzio Road, Observatory 7925, Cape Town, South Africa. ${ }^{4}$ Department of Chemistry, University of Cambridge, Lensfield Road, Cambridge CB2 1EW, UK. ${ }^{5}$ Division of Infectious Diseases, Weill Department of Medicine, Weill Cornell Medical College, New York, NY 10065, USA. ${ }^{6}$ Tuberculosis Research Section, Laboratory of Clinical Immunology and Microbiology, National Institute of Allergy and Infectious Disease, National Institutes of Health,9000 Rockville Pike, Bethesda, MD 20892, USA. ${ }^{凶}$ email: vgm23@cam.ac.uk; tom@cryst. bioc.cam.ac.uk
} 
T uberculosis (TB) is the most prevalent and deadly infectious disease worldwide and remains a global epidemic. Despite the availability of treatment, this disease, caused by Mycobacterium tuberculosis, still claims 1.5 million lives each year ${ }^{1}$. Current treatment regimens are long, which presents an obstacle for patient adherence and imposes a heavy social and economic burden on countries with a high incidence of TB. It is therefore critical to explore novel targets and find new and more effective drugs to combat this disease.

Coenzyme A (CoA) is an essential and ubiquitous co-factor involved in numerous metabolic pathways with a large number of different enzymes requiring it for their activity ${ }^{2}$. CoA is essential for the synthesis of phospholipids, fatty acids, polyketides and non-ribosomal peptides, for the operation of the tricarboxylic acid cycle and in the degradation of lipids ${ }^{3}$. The importance of CoA for essential post-translational modifications of proteins is also well established in both eukaryotes and prokaryotes, with various proteins post-translationally modified by thioester derivatives of CoA (acylation) or CoA itself (phosphopantetheinylation and CoAlation), while several other post-translational modifications depend indirectly on CoA through the mevalonate pathway ${ }^{4-7}$. Furthermore, dephospho-CoA, an intermediate of the CoA pathway, is incorporated into some RNA transcripts during transcription initiation thereby serving as a non-canonical transcription initiating nucleotide ${ }^{8}$. These RNA modifications have functional consequences and occur in both eukaryotes and bacteria $^{8}$. In $M$. tuberculosis, CoA plays a pivotal role in the biosynthesis of complex lipids that are crucial components of the cell wall and required for pathogenicity ${ }^{9}$. It is also needed for the degradation of lipids, including cholesterol, which are the primary source of energy for this organism during infection ${ }^{10,11}$. Given its ubiquitous nature, wide metabolic and functional impact of its inhibition, and lack of sequence conservation between prokaryotes and humans, the CoA pathway is therefore an attractive pathway for drug discovery for many different infectious diseases, including TB.

The biosynthesis of CoA from pantothenic acid (vitamin $\mathrm{B}_{5}$ ) is performed in five steps (Fig. 1), sequentially catalysed by the enzymes pantothenate kinase (CoaA, also known as PanK), phosphopantothenoylcysteine synthetase (CoaB), phosphopantothenoylcysteine decarboxylase (CoaC), phosphopantetheine adenylyltransferase (CoaD) and dephospho-CoA kinase (CoaE). However, in the vast majority of prokaryotes, including $M$. tuberculosis, $\mathrm{CoaB}$ and $\mathrm{CoaC}$ are encoded by a single gene to produce a fused bifunctional enzyme (CoaBC). Transcriptional silencing of individual genes of the CoA biosynthetic pathway of this pathogen identified $\mathrm{CoaBC}$ as uniquely bactericidal within the CoA pathway, highlighting it as a good candidate for drug discovery ${ }^{12}$. Nevertheless, the reported inhibitors for this enzyme are very few in number and almost invariably substrate mimicking ${ }^{13-15}$.

CoaBC converts $4^{\prime}$-phosphopantothenate to $4^{\prime}$-phosphopantetheine in three steps. First, $4^{\prime}$-phosphopantothenate (PPA) reacts with CTP to form $4^{\prime}$-phosphopantothenoyl-CMP with the release of pyrophosphate. This intermediate subsequently reacts with cysteine to form $4^{\prime}$-phosphopantothenoylcysteine (PPC) with the release of CMP, with these two steps being catalysed by $\mathrm{CoaB}$. The product of $\mathrm{CoaB}$ is then decarboxylated by $\mathrm{CoaC}$, an enzyme of the homo-oligomeric flavin-containing decarboxylase (HFCD) protein family, to $4^{\prime}$-phosphopantetheine. X-ray crystal structures have been reported for the individual $\mathrm{CoaB}$ and $\mathrm{CoaC}$ enzymes in several organisms, including a structure of $\mathrm{CoaB}$ from Mycobacterium smegmatis, a close relative of M.tuberculosis. However, a structure of a full-length bifunctional CoaBC had not been determined.

Here we report the structure of the bifunctional CoaBC of $M$. smegmatis at $2.5 \AA$. We identify a previously unknown allosteric site in CoaB and crucially, we report the discovery of the first $M$. tuberculosis CoaBC allosteric inhibitors. Using X-ray crystallography and enzyme kinetic experiments, we define the mode of binding of one of the inhibitors and show its impact on the protein structure and function. These results further illustrate the potential of CoaBC as a drug target in M. tuberculosis.

\section{Results}

Overall structure of CoaBC. As the HFCD protein family of flavin-binding proteins are known to form homo-oligomers ${ }^{16}$, we performed native electrospray-ionisation mass spectrometry (ESIMS) to investigate the stoichiometry of $\mathrm{CoaBC}$, previously proposed to form a dodecamer ${ }^{16}$. Both $M$. tuberculosis CoaBC (MtbCoaBC) (Supplementary Fig. 1a) and M. smegmatis CoaBC

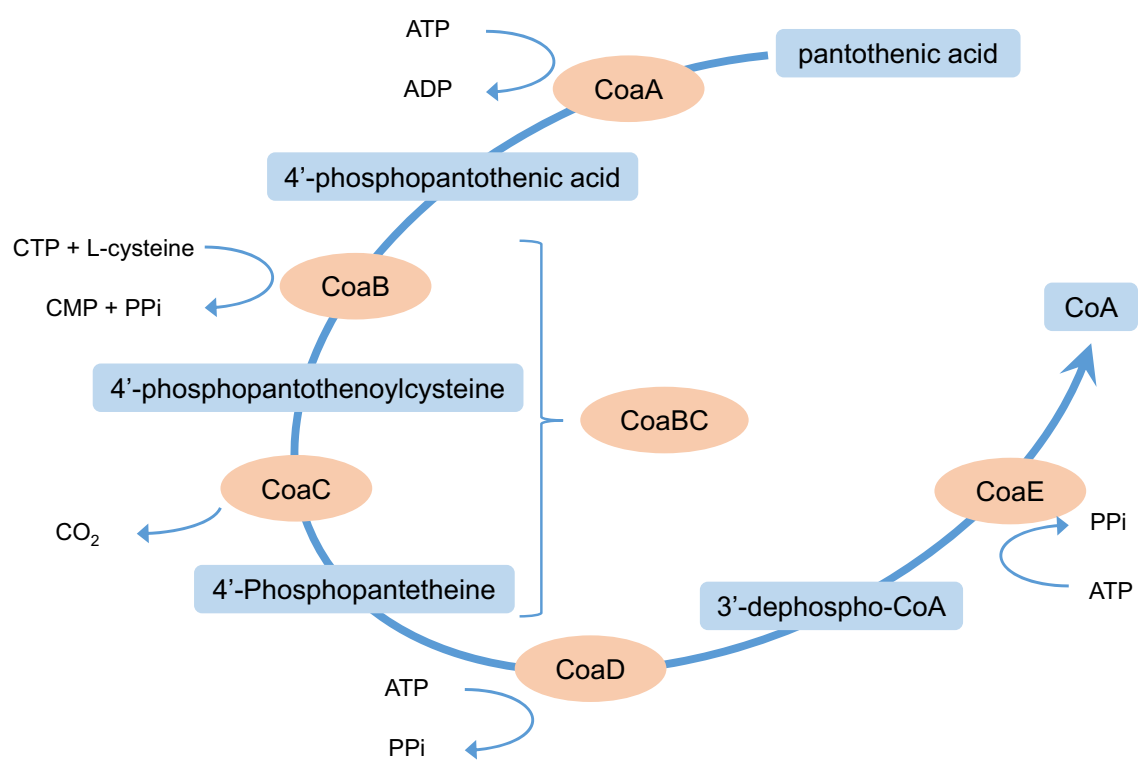

Fig. 1 Coenzyme A biosynthesis pathway. Depiction of the CoA biosynthesis pathway showing all the substrates and products in each biosynthetic step. Enzymes are circled in orange while pathway intermediates are boxed in blue. 


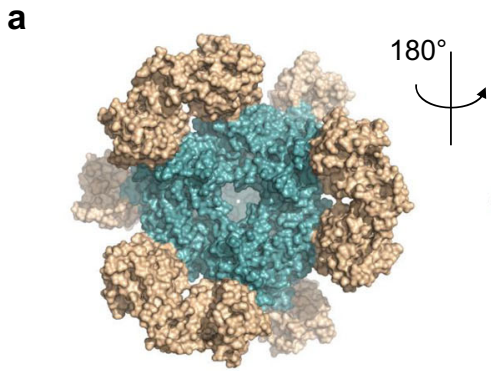

b

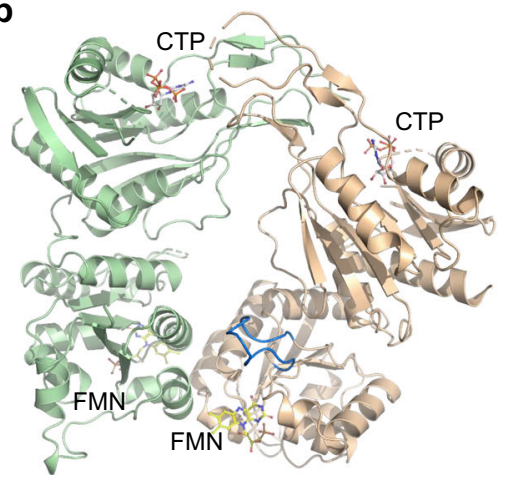

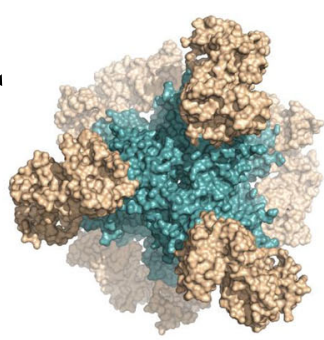

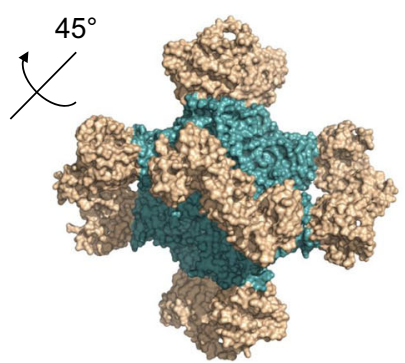

c

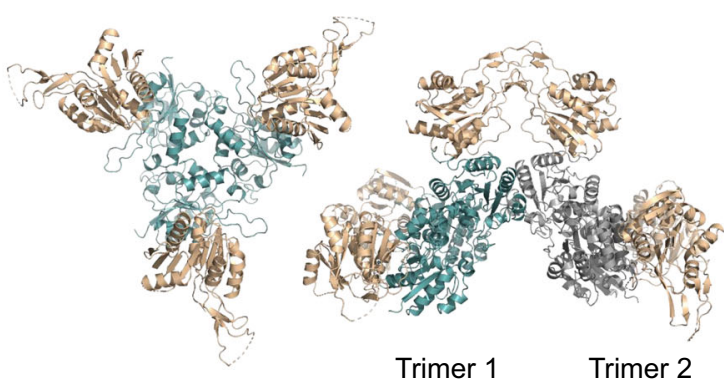

Fig. 2 X-ray crystal structure of FMN and CTP-bound MsmCoaBC. a Full aspect of the dodecameric CoaBC with CoaC represented in teal and CoaB in gold. $\mathbf{b}$ View of a CoaBC dimer with FMN and CTP shown. Each protomer is coloured differently. The CoaC active site flexible flap is highlighted in blue. $\mathbf{c}$ In the left panel, a CoaBC trimer is shown with the $\mathrm{CoaC}$ coloured in teal and $\mathrm{CoaB}$ in gold. On the right panel dimerisation of two CoaBC trimers is shown with $\mathrm{CoaC}$ coloured in teal or grey for different trimers. Each $\mathrm{CoaB}$ forms a dimer with protomers from different trimers.

(MsmCoaBC) (Supplementary Fig. 1b) exclusively exhibited a dodecameric assembly, with no other oligomeric species observed in the spectra, which is consistent with a strong interaction between the subunits of the complex. The dodecamer of $M t b C o a B C$ was centred around the 56+ charge state, with an observed mass of $537 \mathrm{kDa}$, while the dodecamer of $M s m \mathrm{CoaBC}$ was centred around the $52+$ charge state, with an observed mass of $523 \mathrm{kDa}$. While the MsmCoaBC mass matches the expected mass including 12 bound flavin mononucleotide molecules, the $M t b \mathrm{CoaBC}$ mass is $\sim 1 \%$ higher than the expected mass of $530 \mathrm{kDa}$, which can be attributed to non-specific binding of solvent molecules or ions to the protein complexes under the soft ionisation conditions employed.

Structures of a few proteins of the HFCD family have been determined ${ }^{17-21}$. All of these structures show either a homotrimeric or homo-dodecameric arrangement of the flavincontaining Rossmann fold with trimers forming at each of the vertices of the tetrahedron in the case of a dodecameric arrangement ${ }^{18}$. However, all of these proteins, unlike CoaBC, contain only a single functional domain. We solved the structure of $M s m$ CoaBC (PDB: 6TGV) at $2.5 \AA$ resolution (Fig. 2a), in the presence of CTP and FMN (Fig. 2b and Supplementary Fig. 2a, b), using crystals belonging to the $\mathrm{H}_{2}$ space group with an asymmetric unit containing four protomers forming two CoaBC dimers. Data collection and refinement statistics are summarised in (Supplementary Table 1). The final model (residues 2-412) covers both $\mathrm{CoaC}$ and $\mathrm{CoaB}$, but densities for several residues in three loop regions in CoaB are not observed (residues 290-298, 336-342, 363-376). Nevertheless, all these residues except for 375 and 376, can be seen in the MsmCoaB X-ray crystal structure (PDB: 6TH2) that we also solved in this work at $1.8 \AA$. The $N$-terminal CoaC of $M s m$ CoaBC (residues 1-179) forms the same type of dodecameric arrangement seen in other HFCD family proteins, such as the peptidyl-cysteine decarboxylase $\mathrm{EpiD}^{18}$, and it sits at the core of the dodecamer (Fig. 2a, c) with the two domains connected through a small loop region (residues
180-189) that tightly interacts with both. The active site of CoaC sits at the interface between two protomers of one $\mathrm{CoaC}$ trimer and a protomer of an adjacent $\mathrm{CoaC}$ trimer with the FMN site facing inwards towards the hollow centre of the dodecamer (Fig. 3a). A previously described flexible flap that encloses the reaction intermediate bound to Arabidopsis thaliana $\mathrm{CoaC}^{22}$ is also observed in some of the protomers, but in an open conformation (Fig. 2b).

The C-terminal CoaB of MsmCoaBC also displays a Rossmann fold consistent with several other $\mathrm{CoaB}$ structures solved previously, including both the eukaryotic form, in which $\mathrm{CoaB}$ exists as an individual polypeptide, and the bacterial form where $\mathrm{CoaB}$ is typically fused with $\mathrm{CoaC}^{23-25}$. Each $\mathrm{CoaB}$ of Msm CoaBC (residues 190-414) dimerises with a CoaB belonging to an adjacent trimer (Fig. 2c). The full protein resembles a tetrahedron with $\mathrm{CoaB}$ dimers positioned at the six edges and $\mathrm{CoaC}$ trimers at the four vertices (Fig. 2a).

The shortest distance between a pair of $\mathrm{CoaB}$ and $\mathrm{CoaC}$ active sites is $\sim 30 \AA$ (Fig. $3 b$ ). Nevertheless, a flexible loop (residues 362-377) that covers the $4^{\prime}$-phosphopantothenate site, when this substrate binds to the enzyme ${ }^{23}$, can be seen in our MsmCoaB structure, extending away from the active site. A superposition of our $M s m \mathrm{CoaB}$ dimer structure with $\mathrm{Msm}$ CoaBC shows the loop extending towards the $\mathrm{CoaC}$ active site (Fig. 3b). This long loop (15-16 amino acids) is present in all CoaBCs (Supplementary Fig. 3) and it is possible that it helps channelling the substrate from the $\mathrm{CoaB}$ to the $\mathrm{CoaC}$ active site.

The small differences (RMSD $=1.147 \AA$ ) in overall structure of $\mathrm{CoaB}$ dimers in the full-length $\mathrm{Msm} \mathrm{CoaBC}$ and the $\mathrm{MsmCoaB}$ crystal structure solved at $1.8 \AA$ (Supplementary Fig. 4) can be attributed to artefacts of crystal packing. Similarly, the CoaC structure does not seem to differ between full-length Msm CoaBC and the available individual $\mathrm{CoaC}$ structures. However, when $\mathrm{Msm} \mathrm{CoaB}$ (residues 186-414) is expressed alone, the protein does not dimerise in solution and is inactive. This contrasts with E. coli $\mathrm{CoaB}$, which still dimerises and is functional when expressed on its own without 
a

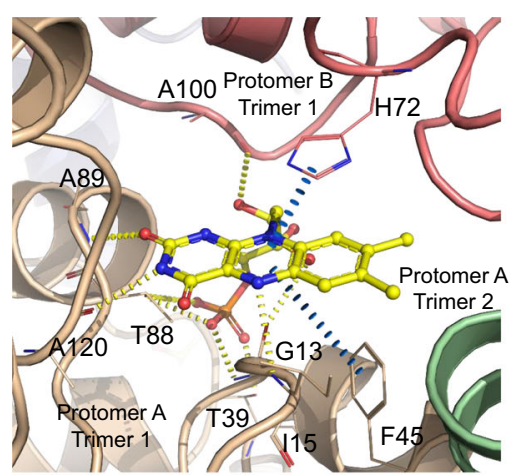

C

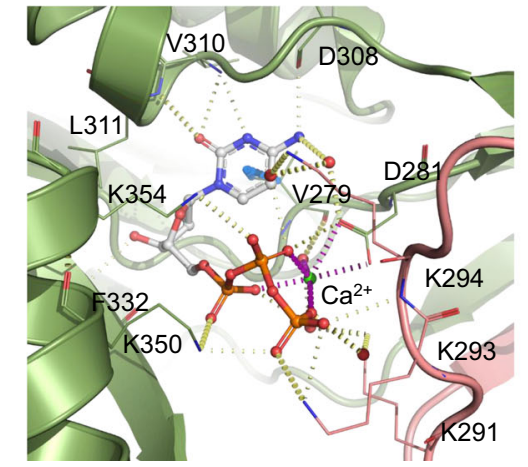

b

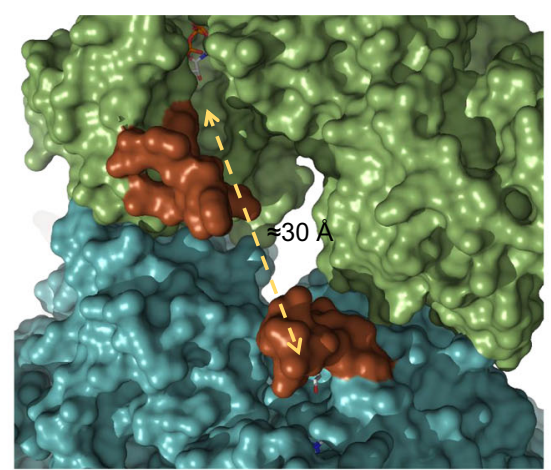

d

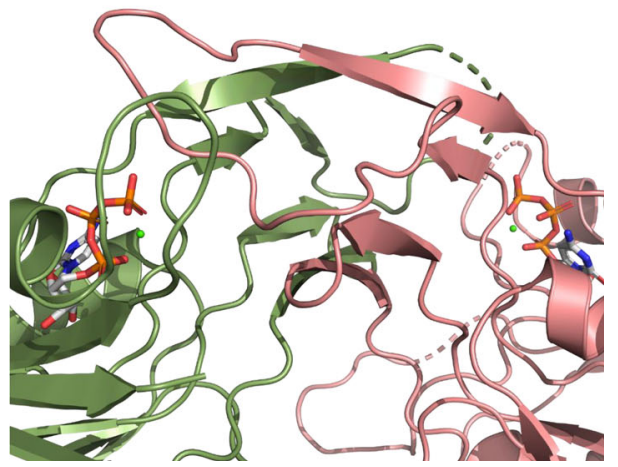

Fig. 3 Detailed view of MsmCoaBC active sites and MsmCoaB dimerisation interface. a View of CoaC active site with FMN bound. The active site sits between two protomers of one trimer (gold and pink) and a third protomer from an adjacent trimer (green). Hydrogen bonds are depicted in yellow and $\pi$-interactions are in blue. $\mathbf{b}$ Superposition of a CoaB crystal structure in green, with full-length CoaBC (teal) showing the active site flaps (brown) of the $\mathrm{CoaB}$ and $\mathrm{CoaC}$ enzymes. c Detailed view of the CTP binding site. Cartoon and residues belonging to each protomer are coloured differently. Hydrogen bonds and $\pi$-interactions are coloured as in $\mathbf{b}$. Important waters are represented as red spheres and calcium as a green sphere. Calcium coordination is depicted in purple. $\mathbf{d}$ CoaB dimerisation interface. Each protomer is coloured as in $\mathbf{c}$.

the $\mathrm{N}$-terminal $\mathrm{CoaC}^{13,26}$. The $\mathrm{CoaB}$ dimer interface is mostly conserved, but there are clear differences in the dimerisation region between $M s m \mathrm{CoaB}$ and $E$. coli $\mathrm{CoaB}$ that could help to explain the different observed oligomerisation patterns (Supplementary Fig. 3). The absence of dimerisation for the $M s m \mathrm{CoaB}$ when expressed alone suggests that the interactions between $\mathrm{CoaC}$ and $\mathrm{CoaB}$ in M. smegmatis, and likely all other Mycobacteriaceae, are fundamental for $\mathrm{CoaB}$ dimerisation and activity. This idea is reinforced by the fact that the residues located at the interface of the two enzymes (CoaB and $\mathrm{CoaC}$ ) are well conserved in all Mycobacteriaceae and somewhat conserved in the sub-order Corynebacterineae, but not outside of this group (Supplementary Fig. 3).

The CoaB dimerisation region forms a $\beta$-sandwich composed of eight anti-parallel $\beta$-strands, related by 2 -fold symmetry, that contacts with the active site (Fig. 3c, d). Comparison of the $M s m \mathrm{CoaB}$ with human $\mathrm{CoaB}$ reveals that the human and many other eukaryotic $\mathrm{CoaBs}^{24}$ possess two extra $\alpha$-helices and $\beta$ strands involved in the dimerisation interface that help stabilise the dimer in the absence of CoaC (Supplementary Fig. 5).

The CoaB active site is enclosed by a loop that extends from the opposing protomer. This loop contains a motif "K-X-K-K", which is widely conserved in bacteria (Supplementary Fig. 3), with few exceptions, and each lysine either interacts directly with the triphosphate group of CTP or through highly coordinated waters (Fig. 3c). Also observed is the coordination of a cation by the triphosphate group and D281 (Fig. 3c and Supplementary Fig. 6). While magnesium or manganese are the favoured cations for CoaB activity ${ }^{27}$, calcium is observed in our structures instead, due to the high concentration present in the crystallisation condition.

CoaBC is regulated by $\mathrm{CoA}$ thioesters. It is known that $\mathrm{CoA}$ biosynthesis is regulated, in many organisms, at the first step of the pathway, which is catalysed by the enzyme CoaA ${ }^{3}$. M. tuberculosis and many other mycobacteria possess a CoaA (type I PanK) as well as CoaX (type III PanK). However, only the type I PanK seems to be active based on studies in $M$. tuberculosis $^{28}$. CoA and its thioesters competitively inhibit E. coli CoaA by binding to the ATP site, with CoA being the strongest regulator ${ }^{29,30}$. Nevertheless, at physiologically relevant levels of CoA there is only a low level inhibition of $\mathrm{CoaA}^{30}$. It is also known that $M$. tuberculosis CoaD, the enzyme that catalyses the fourth step of the pathway, is competitively inhibited by CoA and its product dephospho-CoA ${ }^{31,32}$. However, nothing was known about the regulation of $\mathrm{CoaBC}$ in any organism. We therefore examined the effect of CoA and several of its thioesters (acetylCoA, malonyl-CoA and succinyl-CoA) on MtbCoaBC activity, using a coupled enzymatic assay that quantifies the release of pyrophosphate (EnzChek pyrophosphate assay). Controls were performed to assess the activity of these compounds against the two coupling enzymes and the compounds showed an absence of inhibition at the tested range of concentrations.

Inhibition of $\mathrm{CoaB}$ activity by $\mathrm{CoA}$ and acyl-CoAs was observed, with $\mathrm{IC}_{50}$ values ranging from 38 to $148 \mu \mathrm{M}$, far below the predicted intracellular concentrations of acyl-CoAs ${ }^{33}$, with succinyl-CoA displaying the highest inhibition (Fig. 4a and Table 1). To assess the mode of inhibition of CoA and its thioesters the EnzChek-coupled enzyme assay that measures the release of pyrophosphate was used to follow the first half of the reaction while a CMP quantification assay was used for the second half of the reaction. Competition assays with the three substrates and acetyl-CoA show a competitive mode of inhibition relative to CTP and PPA with a $K_{\mathrm{i}}$ of 22.5 and $22.4 \mu \mathrm{M}$, respectively, and non-competitive inhibition for L-cysteine with a $K_{\mathrm{i}}$ of $62.1 \mu \mathrm{M}$ (Fig. $4 \mathrm{~b}$ and Table 2). In the absence of a crystal 

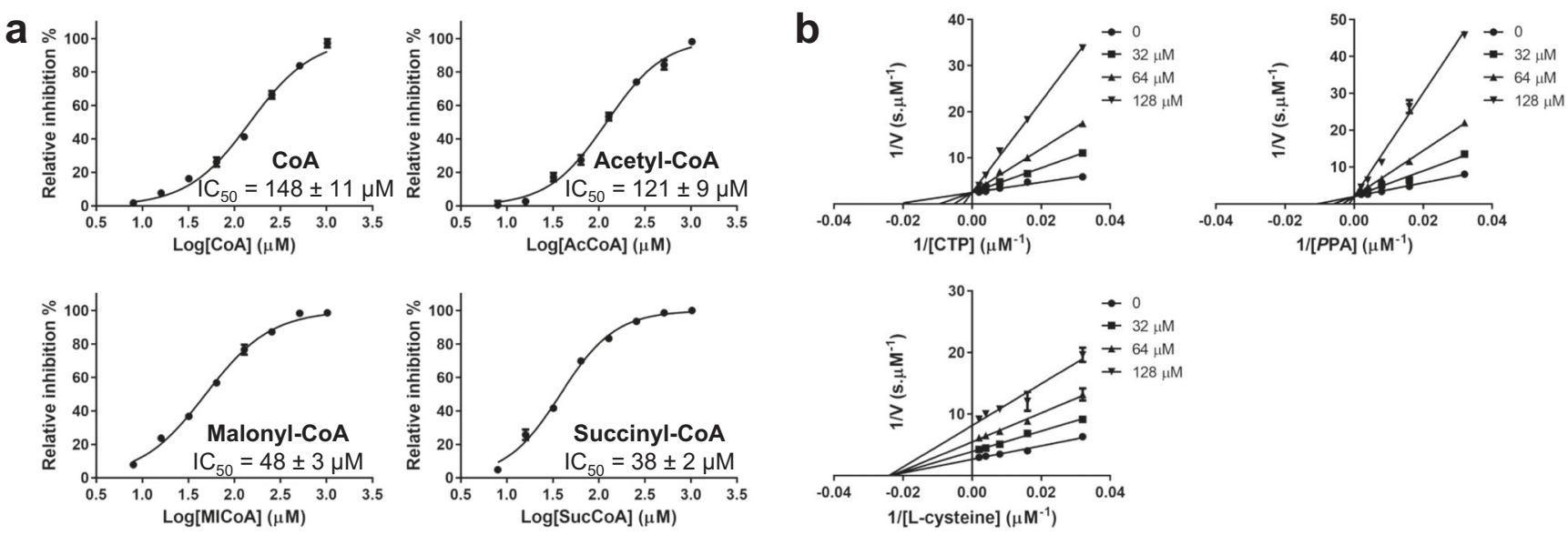

Fig. 4 Regulation of MtbCoaBC by CoA and CoA thioesthers. a Inhibition of MtbCoaBC by CoA, acetyl-CoA, malonyl-CoA and succinyl-CoA. b Lineweaver-Burk plots showing the effect of varying the concentration of each substrate in the presence of different concentrations of acetyl-CoA. Data are presented as average values of three independent experiments with \pm SD. Source data are provided as a source data file.

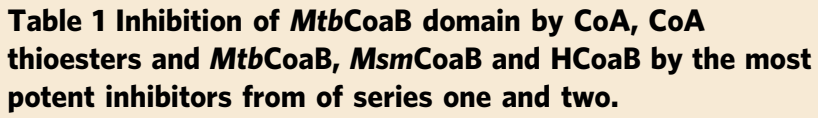

\begin{tabular}{|c|c|c|c|}
\hline Compound & $\begin{array}{l}\text { IC } 50 \text { EnzChek } \\
\text { MtbCoaBC }(\mu \mathrm{M})\end{array}$ & $\begin{array}{l}\text { IC }_{50} \text { EnzChek } \\
\text { HCoaB }(\mu \mathrm{M})\end{array}$ & $\begin{array}{l}\text { IC } \text { Io EnzChek }_{\text {MsmCoaBC }(\mu \mathrm{M})} \\
\end{array}$ \\
\hline CoA & $148 \pm 11$ & & \\
\hline $\mathrm{AcCoA}$ & $121 \pm 9$ & & \\
\hline MICoA & $49 \pm 3$ & & \\
\hline SucCoA & $38 \pm 2$ & & \\
\hline $\begin{array}{l}1 b \\
1 c\end{array}$ & $\begin{array}{c}0.28 \pm 0.05 \\
4.6 \pm 0.4\end{array}$ & $122 \pm 22$ & $0.26 \pm 0.02$ \\
\hline $2 b$ & $0.08 \pm 0.01$ & $60 \pm 7$ & $0.18 \pm 0.02$ \\
\hline $2 c$ & $0.41 \pm 0.03$ & & \\
\hline $2 d$ & $0.54 \pm 0.06$ & & \\
\hline $2 \mathrm{e}$ & $3.0 \pm 0.2$ & & \\
\hline
\end{tabular}

$I_{50}$ values determined using the EnzChek pyrophosphate assay are shown.

Data are presented as average values of three independent experiments with $\pm S D$.

\begin{tabular}{|c|c|c|c|}
\hline Inhibitor & $\begin{array}{l}\text { Variable } \\
\text { substrate }\end{array}$ & $K_{\mathrm{i}}(\mu \mathrm{M})$ & Inibition type \\
\hline \multirow[t]{3}{*}{$\mathrm{AcCoA}$} & CTP & $22.5 \pm 1.7$ & C \\
\hline & PPA & $22.4 \pm 1.4$ & C \\
\hline & L-cysteine & $62.1 \pm 2.0$ & NC \\
\hline \multirow[t]{3}{*}{$1 b$} & CTP & ${ }^{*} 0.222 \pm 0.012$ & UC \\
\hline & PPA & ${ }^{\star} 0.078 \pm 0.005$ & UC \\
\hline & L-cysteine & ${ }^{\star} 0.181 \pm 0.008$ & UC \\
\hline \multirow[t]{3}{*}{$2 b$} & CTP & $0.093 \pm 0.018$ & Mixed \\
\hline & PPA & ${ }^{\star} 0.062 \pm 0.004$ & UC \\
\hline & L-cysteine & ${ }^{\star} 0.055 \pm 0.003$ & UC \\
\hline
\end{tabular}

${ }^{\star}$ For uncompetitive inhibitors $\alpha K_{\mathrm{i}}$ product is shown

\#Abbreviations: $C$ competitive inhibition, NC non-competitive inhibition, UC uncompetitive inhibition.

Data are presented as average values of three independent experiments with \pm SD .

structure to confirm the mode of binding, these results suggest that acyl-CoAs most likely bind to the active site itself, competing directly with CTP and PPA. Interestingly, both acyl-CoAs, involved in fatty acid synthesis, as well as those involved in the
TCA cycle, show inhibition of CoaB, with larger fatty acyl chains showing higher inhibition of CoaB (Fig. 4a).

Identification of CoaB inhibitors using high-throughput screening. Although the CoA biosynthetic pathway is considered an attractive target for drug discovery, CoA pathway inhibitors displaying potent whole cell activity are rare and the few CoaBC inhibitors that have been reported to date are in majority substrate mimicking ${ }^{13,34}$

In order to identify $M t b C$ CaBC inhibitors, we have conducted a high-throughput screen of 215,000 small molecules targeting CoaB activity. To do this, an end-point pyrophosphate quantification assay was used (Biomol Green). The most potent hits identified were compounds $1 \mathrm{a}$ and $2 \mathrm{a}$ with $\mathrm{IC}_{50}$ values of 9 and $3.1 \mu \mathrm{M}$, respectively (Fig. 5 and Supplementary Table 2), originating from two different but related chemical scaffolds. A search was then performed for commercially available analogues. Testing of analogues of the initial hits resulted in the identification of more potent compounds with sub-micromolar $\mathrm{IC}_{50}$ values (Table 1 and Supplementary Table 2, Figs. 5, 6a and Supplementary Fig. 7). Of these, compounds $1 \mathrm{~b}$ and $2 \mathrm{~b}$ (Figs. 5, $6 \mathrm{a}$ and Table 1), with $\mathrm{IC}_{50}$ values of 0.28 and $0.08 \mu \mathrm{M}$, respectively, were identified as the most potent of the two chemical series and therefore were selected for further work.

Selectivity and elucidation of the mode of inhibition. Following the identification of potent $M t b C o a B$ inhibitors we went on to determine their activity against human $\mathrm{CoaB}(\mathrm{HCoaB})$ and $M s m$ CoaBC. Control experiments were first performed to assess compound activity against the two coupling enzymes of the EnzChek assay and the compounds were found to be inactive at $100 \mu \mathrm{M}$. The $\mathrm{IC}_{50}$ values for the most active compounds against $M t b \mathrm{CoaB}$ were re-determined with this assay and the values obtained were in line with the primary screening assay (Supplementary Table 2). Both compounds were also found to be highly selective for mycobacterial enzymes showing activity for $M s m C o a B C$ in a similar range to what was observed for $\mathrm{M} t b \mathrm{CoaBC}$ with $\mathrm{IC}_{50}$ values of 0.26 and $0.18 \mu \mathrm{M}$, respectively, and were two orders of magnitude less active for the human $\mathrm{CoaB}$ (HCoaB) with $\mathrm{IC}_{50}$ values of 122 and $60.4 \mu \mathrm{M}$, respectively (Table 1 and Supplementary Fig. 7).

Competition experiments were then performed between the three CoaB substrates and the two most potent compounds of each chemical series ( $1 \mathrm{~b}$ and $2 \mathrm{~b}$ ) to determine the mode of inhibition. Compound $1 \mathrm{~b}$ showed uncompetitive inhibition for all 
<smiles>O=C(c1ccccc1)c1ccc(O)c(O)c1O</smiles>

$1 \mathrm{a}$<smiles>O=C(c1ccc(O)cc1)c1ccc(O)c(O)c1O</smiles>

$1 \mathrm{~b}$<smiles>Oc1ccc(Cc2ccc(O)c(O)c2O)cc1</smiles>

$1 \mathrm{c}$<smiles>O=c1cc(-c2ccccc2)oc2cc(O)c(O)c(O)c12</smiles><smiles>O=c1cc(-c2ccc(O)c(O)c2)oc2cc(O)c(O)cc12</smiles><smiles>O=c1cc(-c2ccc(O)cc2)oc2cc(O)c(O)c(O)c12</smiles><smiles>Cc1ccc(-c2oc3cc(O)cc(O)c3c(=O)c2O)cc1C</smiles><smiles>O=c1cc(-c2ccc(O)cc2)oc2c(O)c(O)ccc12</smiles>

Fig. 5 Chemical structures of the main compounds of series $\mathbf{1}$ and 2. Chemical structures of the initial hits ( $1 a$ and $2 a$ ) and most potent compounds for series 1 and 2 .

substrates with a $\alpha K_{\mathrm{i}}$ of $0.222,0.078$ and $0.181 \mu \mathrm{M}$, respectively, for CTP, PPA and L-cysteine (Fig. 6b and Table 2), consistent with the compound binding preferentially when the three substrates are bound. Compound $2 \mathrm{~b}$ shows mixed inhibition relative to CTP with a $K_{\mathrm{i}}$ of $0.093 \mu \mathrm{M}$ and uncompetitive inhibition for PPA and L-cysteine with a $\alpha K_{\mathrm{i}}$, respectively, of 0.062 and $0.055 \mu \mathrm{M}$ (Fig. $6 \mathrm{c}$ and Table 2). It is known that CoaB forms the phosphopantothenoyl-CMP intermediate in the absence of L-cysteine ${ }^{35}$ and, due to spatial constraints, it is likely that cysteine can only bind at the active site after the release of pyrophosphate. The data is therefore consistent with compound $1 \mathrm{~b}$ preferentially binding after L-cysteine enters the active site, for the last step of catalysis and the formation of $4^{\prime}$-phosphopantothenoylcysteine and CMP. However, compound $2 \mathrm{~b}$ shows a mixed inhibition for CTP, reflecting a slightly different mechanism of action. These results obtained for both compounds suggest the existence of an allosteric site in the CoaB moiety of $M t b$ CoaBC.

Structural basis for inhibition of CoaB by allosteric inhibitors. In order to elucidate the binding mode of compound $1 \mathrm{~b}$ we used a truncation of the MsmCoaB (residues 187-414) that was previously crystallised before by others in the presence of CTP (PDB: $4 \mathrm{QJI})$ at $2.65 \AA$ resolution. Screening for crystallisation conditions allowed us to find a different CTP containing condition that gave excellent resolution (1.8 $\AA$ ). Comparison of this structure with the full-length MsmCoaBC (Supplementary Fig. 4) showed only minor differences that can be attributed to crystal packing. Hence this crystallisation system could be used to validate CoaB inhibitors binding outside of the CTP site.

$M s m \mathrm{CoaB}$ was co-crystallised with CTP in the absence of compound $1 \mathrm{~b}$ and overnight soaking of the crystals with this compound was performed. A co-crystal structure of $M s m C o a B$ with compound 1b (PDB: 6THC) was obtained and showed that the compound was bound to a site at the dimer interface of CoaB, in a deep cavity that is occluded when the compound is absent (Fig. 7a, b and Supplementary Fig. 8). Each CoaB dimer contains two of these sites, which are formed by a sandwich of eight $\beta$ strands and a long loop that contains the conserved "K-X-K-K" motif. This site opens to the active site and the inhibitor also contacts with D281 that is involved in the coordination of the cation (Fig. 7c). Several residues are shared between the allosteric site and the active site and these include R207, N211, A280, D281 I292, K293 and K294. The opening/closing of this cryptic allosteric site is mediated by the side chain of R207 of the opposing protomer (Fig. $7 \mathrm{~d}$ ) that moves $5.5 \AA$ at the furthest point and, to a smaller extent, by the side chain of F282 that moves $2 \AA$. R207 has previously been shown to be critical for the second half of the reaction catalysed by $\mathrm{CoaB}$, the conversion of the $4^{\prime}$-phosphopantothenoyl-CMP intermediate to PPC, with almost no conversion of the intermediate to PPC detected when this arginine is mutated to glutamine ${ }^{35}$. Given the position of this arginine, it is likely that it is involved in the binding of cysteine. Despite the absence of a crystal structure with cysteine, kinetic data showing uncompetitive inhibition with cysteine is consistent with this.

This allosteric site is comprised of a large group of hydrophobic residues (I209, F282 and L304 of protomer A and L203, I292, P299 and I302 of protomer B) many of which form hydrophobic interactions with compound $1 \mathrm{~b}$ (Fig. 7c). Several $\pi$ interactions between the compound and the protein are also observed and involve the backbone of D281 and the side chain of F282 of protomer A and R207 of protomer B (Fig. 7d). Hydrogen bond interactions are formed with D281 and F282 of protomer A and R207 of protomer B. Water-mediated interactions are also observed for a group of residues that sit at the outer edge of the site (L203, H286 and D303) that is formed exclusively by protomer B (Fig. 7c).

We propose that upon binding of L-cysteine, the R207 side chain moves towards the active site, and is likely involved in stabilising/ orienting L-cysteine to attack the phosphopantothenoyl-CMP intermediate. This movement opens the allosteric site, which allows binding of allosteric inhibitors to the newly created cavity. The allosteric inhibitors will then stabilise the enzyme in its substratebound state with the position of R207 becoming locked by several hydrogen bonds with the side chain of D281 of protomer A, the backbone carbonyl group of I292 and the side chain of D204 of protomer $\mathrm{B}$, but also by the $\pi$-interactions with the compound (Fig. 7c). The residues around this site and crucially R207 are conserved across many microorganisms, suggesting that this allosteric site is present in most, if not all bacterial CoaBCs (Supplementary Figs. 3, 9a). Interestingly, even though overall sequence identity is very low between the human CoaB and $M s m \mathrm{CoaB}(22 \%)$, the human enzyme also contains an arginine equivalent to R207 and a roughly similar interface with several conserved residues, but there are stark differences in the relative position of the residues at this site between the two enzymes (Supplementary Fig. 9b) which can explain the observed large differences in potency of the inhibitors between the human and mycobacterial enzymes.

While we were not able to obtain co-crystal structures with other inhibitors, in silico docking helped to provide a possible explanation for the structure-activity relationship observed for series one and two. The highest-scoring docking pose of 
a

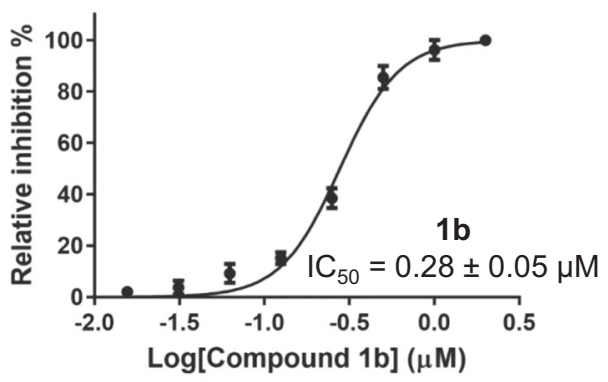

b
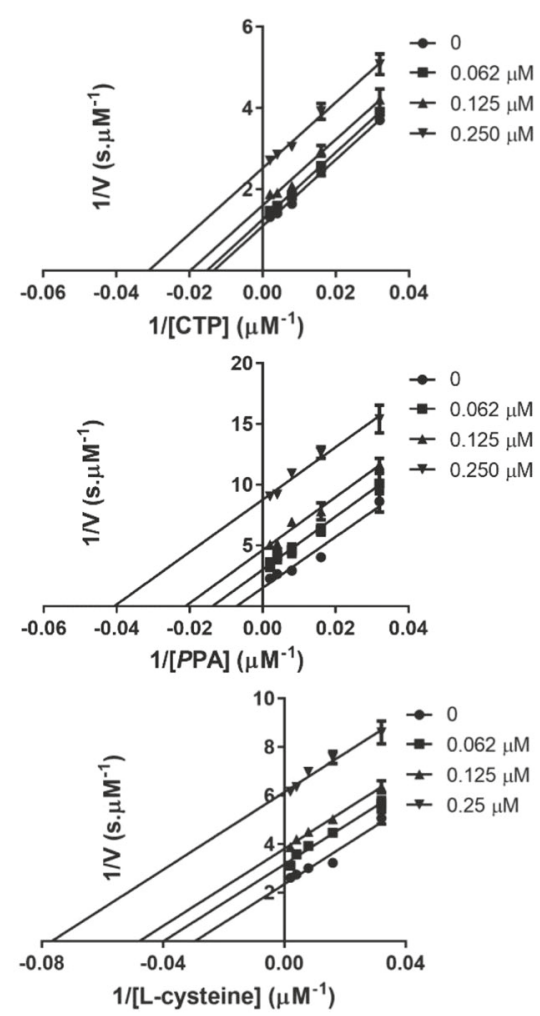

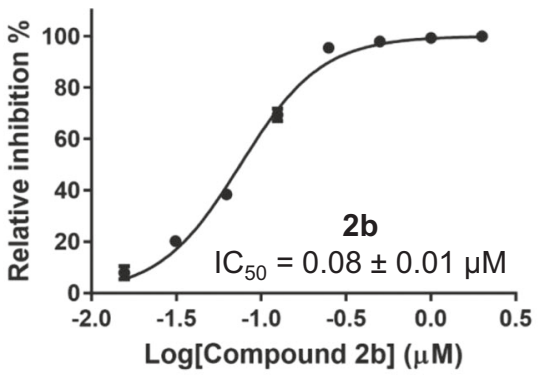

C
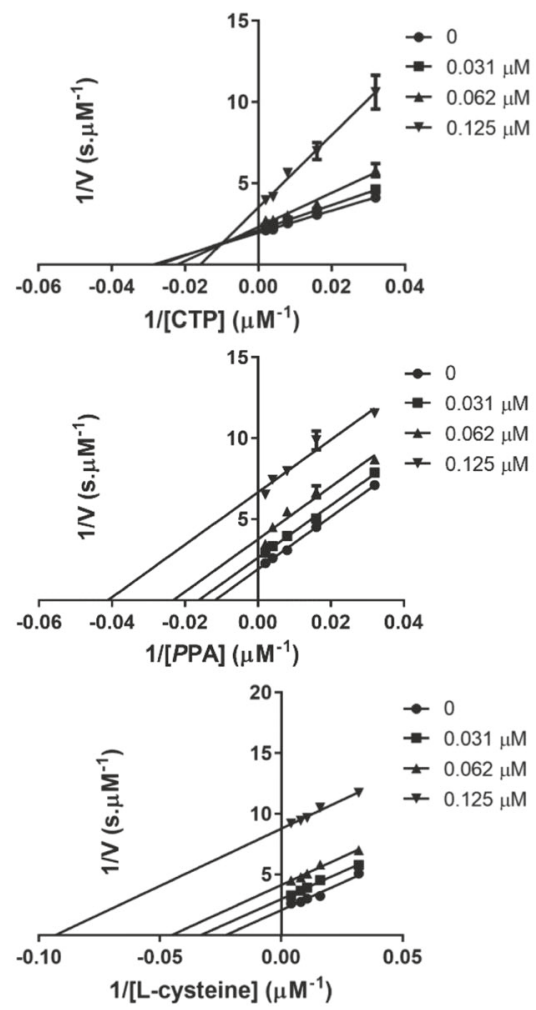

Fig. $\mathbf{6}$ Inhibition of MtbCoaBC by compounds $\mathbf{1} \mathbf{b}$ and $\mathbf{2} \mathbf{b}$. $\mathbf{a}$ Dose response profiles and chemical structure of compounds $1 \mathrm{~b}$ and $2 \mathrm{~b}$ is shown. $\mathbf{b}, \mathbf{c}$ Lineweaver-Burk plots respectively showing the effect of varying concentrations of compounds $1 \mathrm{~b}$ and $2 \mathrm{~b}$ in the presence of varying concentrations of CTP, PPA and L-cysteine. Data are presented as average values of three independent experiments with \pm SD.

compound $1 \mathrm{~b}$, the most potent inhibitor of series one, was almost identical to that observed in the co-crystal structure (Supplementary Fig. 10a), and the analogues for which docking was performed adopted a similar binding pose. The lower activity of compound 1a relative to compound $1 \mathrm{~b}$ could be explained by the loss of water-mediated hydrogen bonds (Fig. $7 \mathrm{c}$ and Supplementary Fig. 10b), while the lower activity of compound 1c could be explained by the loss of the carbonyl group which faces a highly electropositive area of the protein (Supplementary Fig. 10c). Compound $2 \mathrm{~b}$ is predicted to form direct hydrogen bonds at the bottom of the allosteric site, similar to those formed by compound $1 \mathrm{~b}$, but also to interact directly with L203 and $\mathrm{H} 286$, forming extra hydrogen bonds at the top of the allosteric site (Fig. 8). For compound $1 \mathrm{~b}$ the interactions at the top of the site are water mediated (Fig. 7c). This could explain the higher potency of compound $2 \mathrm{~b}$. Compounds $2 \mathrm{c}$ and $2 \mathrm{~d}$ are also predicted to form direct hydrogen bond interactions at the top of the allosteric site, but the interactions at the bottom of the site are not as favourable due to the presence of extra hydroxyl groups (Supplementary Fig. 10d-f). The remaining compounds in series two, which have fewer hydroxyl groups and/or hydroxyl groups in different positions, lose the ability to form hydrogen bonds, consistent with the weaker inhibitory effect observed (Supplementary Table 2). The observed loss of activity of these compounds demonstrates the importance of the catechol group for binding in these two chemical series.

Screening of CoaBC inhibitors against $M$. tuberculosis. The in vitro whole cell activity of the compounds was further evaluated by their ability to inhibit M. tuberculosis growth on different carbon sources. None of the compounds exhibited activity in media containing glycerol or cholesterol as the main carbon source (Table 3). We then tested whether the lack of inhibitory activity could be attributed to the presence of BSA by determining the whole cell activity of the three most potent inhibitors against M. tuberculosis in GAST/Fe minimal media. All the tested compounds exhibited moderate to low activity in this media with compound $2 \mathrm{~b}$ displaying the best activity of the five (Table 3 ). The compounds were then tested against $M$. tuberculosis using a 

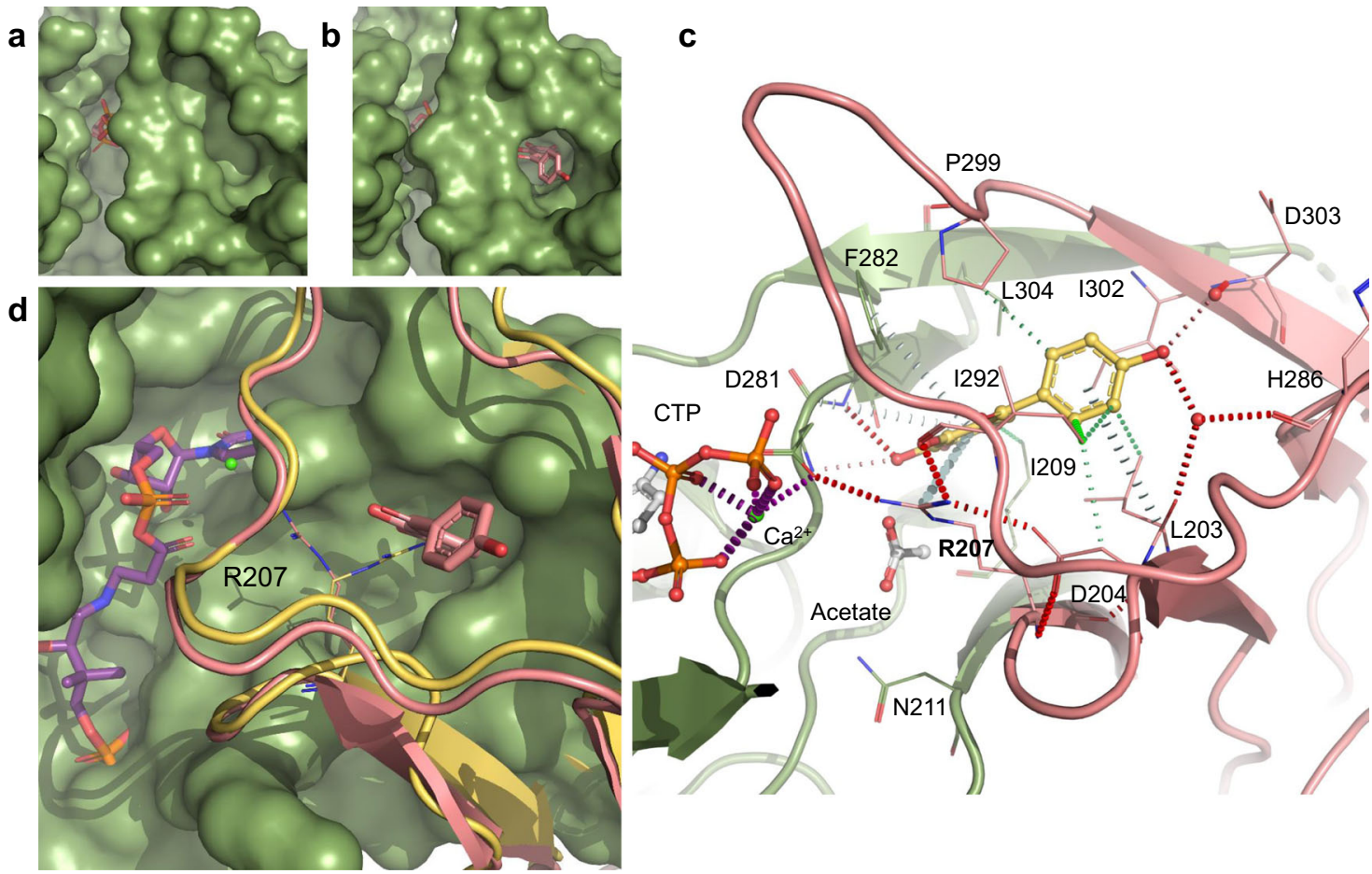

Fig. 7 MsmCoaB X-ray structure showing the cryptic allosteric site. CoaB with the cryptic allosteric site closed (a) and opened conformation (b) with compound $1 \mathrm{~b}$ (pink) bound. c Detailed view of the allosteric site with compound $1 \mathrm{~b}$ (yellow) bound. The individual protomers of the CoaB dimer are coloured in green or pink. Hydrogen bonds are depicted in red, $\pi$-interactions are in grey and hydrophobic interaction in green. Important waters are represented as red spheres and calcium as a green sphere. Calcium coordination is depicted in purple. $\mathbf{d}$ Gating mechanism of the cryptic allosteric site showing the movement of R207 with the closed conformation in yellow and the open conformation in pink. An E. coli structure (PDB: 1U7Z) with the 4'-phosphopantothenoyl-CMP (purple) intermediate bound is superimposed.

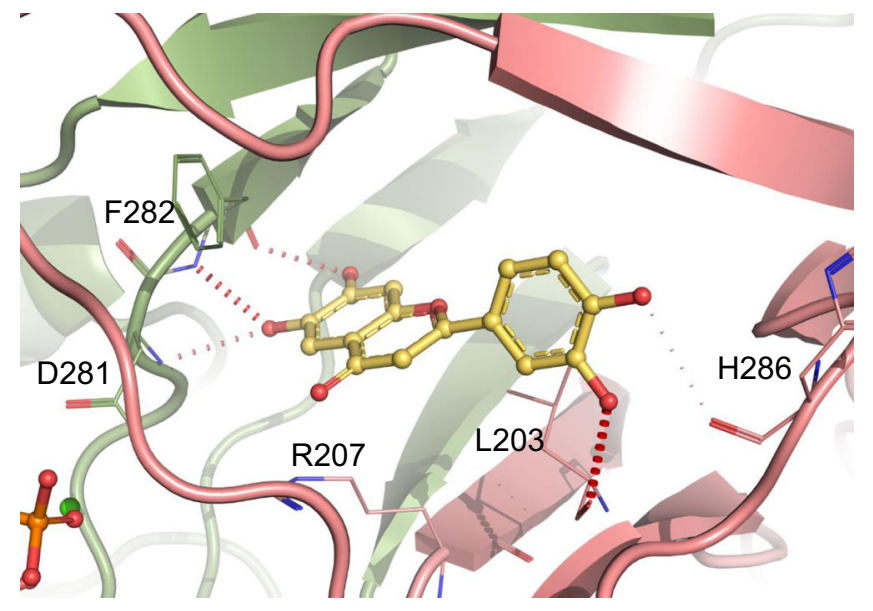

Fig. 8 Docking of compound $2 b$ into MsmCoaB showing the highestscoring pose. Hydrogen bonds are shown in red. The individual protomers of the CoaB dimer are either coloured in green or pink.

CoaBC inducible knockdown ${ }^{12}$ in GAST/Fe minimal media to determine whether the observed anti-mycobacterial activity was related to CoaBC inhibition. However, incremental silencing of CoaBC did not sensitise $M$. tuberculosis further to compounds $1 \mathrm{~b}$ and $2 \mathrm{~b}$, suggesting that the activity of the compounds is not on target. We further tested if the compounds could permeate $M$. tuberculosis cell envelope and reach the cytoplasm. Compound $1 \mathrm{~b}$ exhibited no depletion from the media indicating a lack of uptake or rapid efflux (Supplementary Table 3). Compound 2b, in contrast, exhibited complete depletion from the media but accumulated in M. tuberculosis to levels that accounted for less than $2 \%$

\begin{tabular}{|c|c|c|c|}
\hline Compound & $\begin{array}{l}\text { 7H9/ADC/ } \\
\text { Glycerol }\end{array}$ & $\begin{array}{l}\text { 7H9/Cholesterol/ } \\
\text { Tyloxapol }\end{array}$ & GAST/Fe \\
\hline $1 b$ & $>250$ & $>250$ & 125 \\
\hline $1 c$ & $>250$ & ND & 125 \\
\hline $2 b$ & $>250$ & $>250$ & 50 \\
\hline $2 c$ & $>250$ & $>250$ & 125 \\
\hline $2 d$ & $>250$ & $>250$ & $>250$ \\
\hline $2 e$ & $>250$ & ND & 125 \\
\hline
\end{tabular}

of the amount consumed (Supplementary Table 3), indicative of its likely intrabacterial metabolism ${ }^{36-39}$. These results explain the observed differences in potency between the enzymatic assay and whole cell activity and shows that they are related to low compound permeation/high efflux for $1 \mathrm{~b}$ and metabolism in the case of $2 b$.

\section{Discussion}

CoA is an essential co-factor ubiquitous across all domains of life. For many years, this pathway has been considered an attractive drug target to develop new antibiotics against a wide range of pathogens including $M$. tuberculosis ${ }^{40}$. Furthermore, the recent identification of $\mathrm{CoaBC}$ as a key fragility point in the CoA pathway of this organism ${ }^{12}$, combined with the low sequence 
identity with the human $\mathrm{CoaB}(25 \%)$, makes this enzyme a highly attractive drug discovery target.

While a structure of an individual mycobacterial $\mathrm{CoaB}$ was available, we were aware that the many questions remaining at the start of this work about the organisation and regulation of this bifunctional enzyme could have significant implications for drug discovery. We therefore set out to obtain a full-length structure of a mycobacterial CoaBC and we successfully solved the $M s m$ CoaBC structure, which shares very high sequence identity with the M. tuberculosis orthologue (86\% full-length, $84 \% \mathrm{CoaB}$ enzyme) and hence is a valuable tool for studying $M$. tuberculosis $\mathrm{CoaBC}$. The organisation of $\mathrm{CoaBC}$ is similar to other HFCD family proteins ${ }^{18}$ but unique in the sense that it contains more than one domain and highlights how the arrangement of the fused enzymes is essential for mycobacterial $\mathrm{CoaB}$ dimerisation and function. This fused arrangement might also help to channel the $\mathrm{CoaB}$ product to the $\mathrm{CoaC}$ active site more effectively. The human $\mathrm{CoaB}$ and other eukaryotic orthologues form stable dimers due to the extra dimerisation region (Supplementary Fig. 5), but it is also known in yeast that the entire CoA pathway assembles into a metabolon centred on $\mathrm{CoaC}^{41,42}$ (known as CAB3). This hints that close proximity between the different active sites of the CoA enzymes is desirable and that substrate channelling of products and substrates between different enzymes might be important in this pathway. It is not clear at this point if such an arrangement for the entire CoA pathway is also present in bacteria.

Regulation of the CoA biosynthesis pathway was known to occur for other enzymes of the pathway through feedback inhibition by $\mathrm{CoA}$, but no information was available for $\mathrm{CoaBC}$. We demonstrate that both $\mathrm{CoA}$, as well as several CoA thioesters, regulate $\mathrm{CoaBC}$ by inhibiting $\mathrm{CoaB}$ activity, and that these molecules act competitively for CTP and PPA and noncompetitively for L-cysteine. This is consistent with these molecules binding to the $\mathrm{CoaB}$ active site but not to the L-cysteine sub-site. CoA and acyl-CoAs inhibit both CoaA and CoaD enzymes to varying extents $\mathrm{s}^{30,32,43}$. However, the inhibitory effect of CoA and its thioesters on the activity of these enzymes is lower when compared to what we observed in $\mathrm{CoaBC}$ and consequently the impact of the intracellular level of these molecules will be predominant in CoaBC. We therefore report a new and important mechanism of regulation of "de novo" CoA biosynthesis, mediated by the action of $\mathrm{CoA}$ thioesters on CoaBC. Since the reported intracellular levels of these molecules ${ }^{33}$ are normally above the observed $\mathrm{IC}_{50}$, the activity of CoaBC is highly inhibited. This correlates well with previous work showing that "de novo" CoA biosynthesis closely matches dilution due to cell division ${ }^{44}$. However, the data for intracellular concentrations of CoA and CoA thioesters, as well as CoA half-life was not obtained for mycobacteria, and both interspecies differences along with variations in growth conditions may affect these conclusions.

Although the CoA pathway and CoaBC have been the subject of many drug discovery efforts, few non-substrate-mimicking inhibitors of CoaBC have been reported ${ }^{13}$. Our work identifies two related chemical scaffolds that potently inhibit the activity of the $\mathrm{CoaB}$ moiety of $M t b \mathrm{CoaBC}$ through a cryptic allosteric site that sits in the dimer interface region of the CoaB enzyme. This site is closed in the CTP-bound structure, by the side chain of R207 a residue known to be involved in the second and final step of the reaction catalysed by $\mathrm{CoaB}$ - the conversion of the 4'phosphopantothenoyl-CMP intermediate to $\mathrm{PPC}^{35}$. Considering the role of this residue in the final step of product formation and that compound $\mathrm{lb}$ shows uncompetitive inhibition relative to all $\mathrm{CoaB}$ substrates, we propose that the opening of this site occurs upon binding of the final substrate L-cysteine. Currently it is not clear whether this allosteric site is exploited by a natural ligand, as we were unable to identify such a biomolecule. Nevertheless, the conservation of residues at this site, across a variety of bacteria, indicates that this feature might be common to many, if not all, bacterial CoaBs.

The different mechanism of inhibition between compounds $1 \mathrm{~b}$ and $2 b$ in relation to CTP is difficult to explain without a structure of a complex between $\mathrm{CoaB}$ and $2 \mathrm{~b}$ and docking does not offer further insight. However the observed mixed inhibition model for CTP in the case of compound $2 \mathrm{~b}$ might be due to the fact that this compound is more sterically bulky than $1 b$ and slight movements of residues at the bottom of the allosteric site (A280 and D281) are required to accommodate the compound and that these movements are blocked in the crystal. This correlates well with the fact that no crystal structure of compounds of series 2 could be obtained even when soaking at high concentrations.

Drug discovery against $M$. tuberculosis is rich in examples of compounds with potent activity against an essential enzyme but with a complete lack of whole cell activity due to the impermeable cell wall of this organism, efflux pumps, target modification enzymes and extensive capacity to metabolise compounds ${ }^{45}$. The modest in vitro whole cell activity displayed by the $\mathrm{CoaB}$ inhibitors reported in this work is off target and relates to the characteristics of $M$. tuberculosis with compound $1 \mathrm{~b}$ being unable to reach the cytoplasm and $2 \mathrm{~b}$ suffering metabolism. Nevertheless, the biochemical and structural data described herein further validate $\mathrm{CoaBC}$ as a promising anti-tubercular drug target by showing an allosteric site that can be targeted by potent and selective inhibitors.

\section{Methods}

Cloning and protein purification. M. tuberculosis and M. smegmatis coaBC genes were amplified from genomic DNA of $M$. tuberculosis $\mathrm{H} 37 \mathrm{Rv}$ strain, obtained from ATCC (ATCC25618D-2), using the primers MtbBC28S-F and MtbBC28S-R (Supplementary Table 4), and genomic DNA of M. smegmatis $\mathrm{mc}^{2} 155$, using the primers $M s m$ BC28S-F and MsmBC28S-R (Supplementary Table 4), and cloned into a pET28a vector (Novagen), modified to include an $\mathrm{N}$-terminal 6xHis-SUMO tag. The M. smegmatis coaB construct was obtained from the Seattle Structure Genomics Center for Infectious Disease. An E. coli optimised Human CoaB gene was ordered from Thermofisher and cloned into pHAT4 ${ }^{46}$ using NcoI and HindIII restriction sites. The same protein purification protocol was used for both $M$. tuberculosis and M. smegmatis CoaBC constructs.

E. coli BL21(DE3) containing pET28aSUMO-CoaBC was grown in 2XYT media at $37^{\circ} \mathrm{C}$ until an O.D. ${ }_{600}=0.6$. IPTG was then added to a final concentration of 0.5 $\mathrm{mM}$ and the temperature changed to $18^{\circ} \mathrm{C}$ for $18-20 \mathrm{~h}$. Cells were then harvested by centrifugation, re-suspended in $50 \mathrm{mM}$ TRIS $\mathrm{pH} 8.0,250 \mathrm{mM} \mathrm{NaCl}, 20 \%$ (w/v) glycerol, $20 \mathrm{mM}$ imidazole, $5 \mathrm{mM} \mathrm{MgCl}_{2}$ with protease inhibitors tablets (Roche) and DNAseI (Sigma). Cells were lysed with an Emulsiflex (Avestin) and the resultant cell lysate was centrifuged at $27,000 \mathrm{x} g$ for $30 \mathrm{~min}$ to remove cell debris Recombinant CoaBCs were purified with a HiTrap IMAC Sepharose FF column (GE-Healthcare), equilibrated with $50 \mathrm{mM}$ TRIS pH 8.0, $250 \mathrm{mM} \mathrm{NaCl}, 20 \%$ (w/v) glycerol and $20 \mathrm{mM}$ imidazole. Elution was performed in the same buffer with $500 \mathrm{mM}$ imidazole. Protein was dialysed in $25 \mathrm{mM}$ TRIS pH 8 and $150 \mathrm{mM} \mathrm{NaCl}$ and the SUMO tag was cleaved overnight at $4{ }^{\circ} \mathrm{C}$ by adding Ulp1 Protease at a 1:100 ratio. CoaBC was concentrated and loaded on a Superdex 200 column equilibrated with $25 \mathrm{mM}$ TRIS pH $8.0,150 \mathrm{mM} \mathrm{NaCl}$. Fraction purity was determined by SDS-page and the purest fractions were pooled, concentrated to $\sim 10 \mathrm{mg} \mathrm{mL}^{-1}$ for $M t b C o a B C$ and $30 \mathrm{mg} \mathrm{mL}^{-1}$ for $M s m$ CoaBC, flash frozen in liquid nitrogen and stored at $-80^{\circ} \mathrm{C}$.

E. coli $\mathrm{BL} 21(\mathrm{DE} 3)$ containing the $M$. smegmatis $\mathrm{CoaB}$ construct with a $\mathrm{N}$-terminal non-cleavable $6 \mathrm{xHis}$ tag was grown and harvested as above and resuspended in $20 \mathrm{mM}$ HEPES pH 7.0, $500 \mathrm{mM} \mathrm{NaCl}, 20 \mathrm{mM}$ imidazole, $5 \mathrm{mM}$ $\mathrm{MgCl}_{2}$ with protease inhibitors tablets (Roche) and DNAseI (Sigma). Cells were lysed with an Emulsiflex (Avestin) and cell lysate was centrifuged at 27,000x $g$ for 30 mins to remove cell debris. Recombinant M. smegmatis CoaB was purified with a HiTrap IMAC Sepharose FF column (GE-Healthcare), equilibrated with $20 \mathrm{mM}$ HEPES pH 7.0, $500 \mathrm{mM} \mathrm{NaCl}$ and $20 \mathrm{mM}$ imidazole. Elution was carried out in the same buffer with $500 \mathrm{mM}$ imidazole. Protein was concentrated and loaded on a Superdex 200 column equilibrated with $20 \mathrm{mM}$ HEPES pH 7.0 and $500 \mathrm{mM} \mathrm{NaCl}$ Fraction purity was assessed by SDS-page and the purest fractions were pooled concentrated to $22 \mathrm{mg} \mathrm{mL}^{-1}$, flash frozen in liquid nitrogen and stored at $-80^{\circ} \mathrm{C}$.

E. coli BL21(DE3) containing a human CoaB construct with a cleavable $N$ terminal $6 \mathrm{xHis}$ tag was grown and harvested as above and re-suspended in $50 \mathrm{mM}$ TRIS pH 8.0, $250 \mathrm{mM} \mathrm{NaCl}, 20 \mathrm{mM}$ imidazole, $5 \mathrm{mM} \mathrm{MgCl}_{2}$ with protease 
inhibitors tablets (Roche) and DNAseI (Sigma). Cells were lysed using a sonicator and cell lysate was centrifuged at 27,000x $g$ for 30 mins to remove cell debris. Recombinant Human CoaB was purified with a HiTrap IMAC Sepharose FF column (GE-Healthcare), equilibrated with $50 \mathrm{mM}$ TRIS pH $8.0,250 \mathrm{mM} \mathrm{NaCl}$ and $20 \mathrm{mM}$ imidazole. Elution was performed in the same buffer with $300 \mathrm{mM}$ Imidazole. Protein was dialysed in $25 \mathrm{mM}$ TRIS pH 8 and $150 \mathrm{mM} \mathrm{NaCl}$ and the His tag was cleaved overnight at $4{ }^{\circ} \mathrm{C}$ by adding TEV Protease at a 1:50 ratio. Human $\mathrm{CoaB}$ was concentrated and loaded on a Superdex 200 column equilibrated with $25 \mathrm{mM}$ TRIS pH 8.0, $150 \mathrm{mM} \mathrm{NaCl}$. Fraction purity was determined by SDSpage and the purest fractions were pooled, concentrated to $\sim 10 \mathrm{mg} \mathrm{mL}^{-1}$, flash frozen in liquid nitrogen and stored at $-80^{\circ} \mathrm{C}$. SDS-PAGE images showing the pure enzymes are given in (Supplementary Fig. 11).

Native mass spectrometry. Spectra were recorded on a Synapt HDMS mass spectrometer (Waters) modified for studying high masses. MtbCoaBC and Msm CoaBC were exchanged into $\mathrm{NH}_{4} \mathrm{OAc}(500 \mathrm{mM}, \mathrm{pH}$ 7.0) solution using Micro Bio-Spin 6 chromatography columns (Bio-Rad). A sample volume of $2.5 \mu \mathrm{L}$ was injected into a borosilicate emitter (Thermo Scientific) for sampling. Instrument conditions were optimised to enhance ion desolvation while minimising dissociation of macromolecular complexes. Typical conditions were capillary voltage $1.8-2.0 \mathrm{kV}$, sample cone voltage $100 \mathrm{~V}$, extractor cone voltage $1 \mathrm{~V}$, trap collision voltage $60 \mathrm{~V}$, transfer collision voltage $60 \mathrm{~V}$, source temperature $20^{\circ} \mathrm{C}$, backing pressure 5 mbar, trap pressure $3-4 \times 10^{-2}$ mbar, IMS $\left(\mathrm{N}_{2}\right)$ pressure $5-6 \times 10^{-1}$ mbar and TOF pressure $7-8 \times 10^{-7} \mathrm{mbar}$. Spectra were calibrated externally using caesium iodide. Data acquisition and processing were performed using MassLynx 4.1 (Waters).

Crystallisation. For both full-length $M s m \mathrm{CoaBC}$ and $M s m \mathrm{CoaB}$ alone, the crystallisation screens and optimisation were performed at $18^{\circ} \mathrm{C}$ using the sitting-drop vapour diffusion method. For CoaBC $300 \mathrm{~nL}$ of pure protein at $30 \mathrm{mg} \mathrm{mL}^{-1}$, preincubated with $3 \mathrm{mM} \mathrm{CTP}$ and $10 \mathrm{mM} \mathrm{MgCl}_{2}$, was mixed in 1:1 and 1:2 (protein to reservoir) ratio with well solution using a mosquito robot (TTP labtech). Initial conditions were obtained in the Classics lite crystallisation screen (Qiagen), solution 1. Crystals obtained in this condition diffracted poorly, therefore several rounds of optimisation were performed. The final optimised condition consisted of $0.1 \mathrm{M}$ BisTris pH 6.5, $10 \mathrm{mM} \mathrm{CoCl} 20.8 \mathrm{M} \mathrm{1,6-hexanediol.} \mathrm{Crystals} \mathrm{appeared} \mathrm{after}$ three days in both conditions. A cryogenic solution was prepared by adding ethylene glycol up to $30 \%(\mathrm{v} / \mathrm{v})$ to the mother liquor. Crystals were briefly transferred to this solution, flash frozen in liquid nitrogen and stored for data collection.

For $M s m C o a B, 200 \mathrm{~nL}$ of pure protein at $22-24 \mathrm{mg} \mathrm{mL}^{-1}$ with $10 \mathrm{mM}$ CTP was mixed in 1:1 ratio with well solution using a Phoenix robot (Art Robbins). Crystals were obtained in Wizards classics III\&IV (Rigaku) solution G4 consisting of 20\% (w/v) PEG 8000, 0.1 M MES pH 6.0 and $0.2 \mathrm{M}$ calcium acetate. Crystals appeared after 2 days.

To obtain ligand-bound structures, soaking was performed using the hangingdrop vapour diffusion method as follows: $2 \mu \mathrm{L}$ of a solution containing $20 \%(\mathrm{w} / \mathrm{v})$ PEG 8000, 0.1 M MES pH 6.0, 0.2 M calcium acetate, $0.25 \mathrm{M} \mathrm{NaCl} 10 \%(\mathrm{v} / \mathrm{v})$ DMSO and $1-5 \mathrm{mM}$ inhibitors was left to equilibrate against $500 \mu \mathrm{L}$ of reservoir solution for 3 days. Crystals were then transferred to the pre-equilibrated drops and incubated for $24 \mathrm{~h}$. A cryogenic solution was prepared by adding

2-methyl-2,4-pentanediol up to $25 \%(\mathrm{v} / \mathrm{v})$ to mother liquor. Crystals were briefly transferred to this solution, flash frozen in liquid nitrogen and stored for data collection.

Data collection and processing. The data sets were collected at stations $\mathrm{I} 02$ and I03 at Diamond Light Source (Oxford, UK). The diffraction images were processed with AutoPROC ${ }^{47}$ using XDS ${ }^{48}$ for indexing and integration with AIMLESS ${ }^{49}$ and TRUNCATE ${ }^{50}$ from CCP4 Suite ${ }^{51}$ for data reduction, scaling and calculation of structure factor amplitudes and intensity statistics.

Structure solution and refinement. $\mathrm{Msm} \mathrm{CoaB}$ and $\mathrm{MsmCoaBC}$ structures were solved by molecular replacement using PHASER ${ }^{52}$ from the PHENIX software package ${ }^{53}$. For $M s m \mathrm{CoaB}$, the atomic coordinates of $M s m \mathrm{CoaB}$ structure (PDB: $4 \mathrm{QJI})$ were used as a search model. Ligand-bound structures were solved using our highest resolution $M s m \mathrm{CoaB}$ apo form structure (PDB: 6TH2). For MsmCoaBC, atomic coordinates of Arabidopsis thaliana CoaC (PDB: 1MVL) ${ }^{22}$ and our highest resolution $\mathrm{CoaB}$ structure (PDB: 6TH2) were used as search models. Model building was done with $\mathrm{Coot}^{54}$ and refinement was performed in PHENIX ${ }^{53}$. Structure validation was performed using Coot and PHENIX tools ${ }^{53,54}$. All figures were prepared using Pymol (The PyMOL Molecular Graphics System, Version 2.0 Schrödinger, LLC.) and ligand interactions calculated with Arpeggio ${ }^{55}$.

High-throughput screening. Potential inhibitors of $M t b C o a B C$ were assessed at room temperature using a PHERAstar microplate reader (BMG Labtech). Pyrophosphate produced by $\mathrm{CoaB}$ was converted to two molecules of inorganic phosphate using a pyrophosphatase. Phosphate was then detected using the BIOMOL $^{\oplus}$ Green reagent (Enzo Life Sciences), which when bound to phosphate absorbs light at $650 \mathrm{~nm}$. An end-point assay was carried out in clear, flat-bottom, polystyrene, 384-well plates (Greiner) in an $50 \mu \mathrm{L}$ reaction volume containing
$100 \mathrm{mM}$ TRIS, $\mathrm{pH} 7.6,1 \mathrm{mM} \mathrm{MgCl} 2,1 \mathrm{mM}$ TCEP, $0.03 \mathrm{U} / \mathrm{mL}$ pyrophosphatase, $2 \mu \mathrm{M}$ CTP, $40 \mu \mathrm{M}$ L-cysteine, $30 \mu \mathrm{M}$ PPA and $30 \mathrm{nM} \mathrm{MtbCoaBC}$. Assays were performed by adding $25 \mu \mathrm{L}$ of a 2 -times concentrated reaction mixture containing all components with the exception of the enzymes to all wells, and the reactions started by adding $25 \mu \mathrm{L}$ of a 2 -times concentrated enzyme mixture. The reaction was carried out for $2 \mathrm{~h}$ at room temperature, before $50 \mu \mathrm{L}$ of BIOMOL ${ }^{\oplus}$ Green reagent was added and incubated for a further $20 \mathrm{~min}$ prior to reading.

\section{Inorganic pyrophosphatase-purine nucleoside phosphorylase PNP-PPlase} assay. The commercially available EnzChek pyrophosphate assay kit (E-6645) (Life Technologies) was used for this assay. The final reaction composition used was $0.03 \mathrm{U} / \mathrm{mL}$ inorganic pyrophosphatase, $1 \mathrm{U} / \mathrm{mL}$ purine nucleoside phosphorylase, $1 \mathrm{mM} \mathrm{MgCl} 2,200 \mu \mathrm{M}$ MESG, $100 \mathrm{mM}$ TRIS pH 7.5, $1 \mathrm{mM}$ TCEP, $2 \%$ DMSO, $32 \mathrm{nM}$ MtbCoaBC or MsmCoaBC, $125 \mu \mathrm{M}$ CTP, $125 \mu \mathrm{M}$ PPA, $500 \mu \mathrm{M} \mathrm{L}-$ cysteine, and various concentrations of compounds being tested for inhibition, all prepared from DMSO stock solutions (compounds of series one and two) or water ( $\mathrm{CoA}$ and $\mathrm{CoA}$ thioesters). In the assays with $\mathrm{HCoaB}$ an enzyme concentration of $1 \mu \mathrm{M}$ was used instead. Controls were performed to assess the activity of all the compounds tested in this work against the two coupling enzymes and the compounds showed an absence of inhibition at the tested range of concentrations. Assays were performed on either a CLARIOstar or PHERAstar microplate reader (BMG Labtech) in 96-well plates (Greiner). A substrate mixture containing the substrates and the inhibitor was pre-incubated at $25^{\circ} \mathrm{C}$ for $10 \mathrm{~min}$. An enzyme solution was prepared and separately pre-incubated at $25^{\circ} \mathrm{C}$ for $10 \mathrm{~min}$. The reaction was initiated by the addition of the substrates to the solution containing the enzyme to a final volume of $75 \mu \mathrm{L}$. Enzymatic activity was monitored by following the absorbance at $360 \mathrm{~nm}$ for $30 \mathrm{~min}$ (100 cycles/20 s each cycle) and only the steady-state region of the assay was used for data analysis. Assays were performed in triplicates, including a negative control (lacking PPA) and a positive control (lacking inhibitor).

Competition assays to assess the first half of the $\mathrm{CoaB}$ enzymatic reaction were performed using the same conditions but with variable substrate concentrations $(31.25,62.5,125,250$ and $500 \mu \mathrm{M}$ for CTP and PPA.

CMP quantification assay. To assess the second half of the CoaB enzymatic reaction the release of CMP was monitored using an I-Class UPLC (waters). The $75 \mu \mathrm{L}$ enzymatic reactions contained $1 \mathrm{mM} \mathrm{MgCl} 2,100 \mathrm{mM}$ TRIS $\mathrm{pH} 7.5,1 \mathrm{mM}$ TCEP, 2\% DMSO, $32 \mathrm{nM} \mathrm{MtbCoaBC,} 125 \mu \mathrm{M}$ CTP, $125 \mu \mathrm{M}$ PPA, variable concentrations of L-cysteine $(31.25 \mu \mathrm{M}, 62.5 \mu \mathrm{M}, 93.75 \mu \mathrm{M} 125 \mu \mathrm{M}$ and $250 \mu \mathrm{M})$, and various concentrations of compounds $1 \mathrm{~b}, 2 \mathrm{~b}$ (prepared from DMSO stocks) and acetyl-CoA. Reactions were incubated at $25^{\circ} \mathrm{C}$ and stopped by adding $5 \mu \mathrm{L}$ of EDTA to a final concentration of $20 \mathrm{mM}$ at $5 \mathrm{~min}$ intervals for a period of $15 \mathrm{~min}$ $120 \mu \mathrm{L}$ of mobile phase solvent $\mathrm{A}$ ( $0.1 \%$ formic acid in water) was added to each of the reactions and $10 \mu \mathrm{L}$ of every reaction were injected into an Acquity UPLC HSS T3 column, $2.1 \mathrm{~mm}$ diameter, $150 \mathrm{~mm}$ length and with a particle size of $1.8 \mu \mathrm{m}$ (Waters) and eluted using a gradient elution consisting of Mobile Phase A: $0.1 \%$ formic acid in water and mobile phase B: $0.1 \%$ formic acid in $100 \%$ acetonitrile for $4 \mathrm{~min}$. The absorbance was monitored at $280 \mathrm{~nm}$ using a photodiode array (PDA) detector (Waters). All reactions were carried out in triplicate.

\section{M. tuberculosis strains and MIC measurements. MIC determination for} M. tuberculosis H37RvMA was performed as previously described ${ }^{56}$ in the following media: 7H9/ADC/glycerol (4.7 g/L Difco Middlebrook 7H9 base, $100 \mathrm{~mL} / \mathrm{L}$ Middlebrook albumin (BSA)-dextrose-catalase (ADC) Difco Middlebrook, $0.2 \%$ glycerol and $0.05 \%$ Tween-80), $7 \mathrm{H} 9 /$ Cholesterol/Tyloxapol $(4.7 \mathrm{~g} / \mathrm{L} 7 \mathrm{H} 9$ base, $0.81 \mathrm{~g} / \mathrm{L} \mathrm{NaCl}$, $24 \mathrm{mg} / \mathrm{L}$ cholesterol, $5 \mathrm{~g} / \mathrm{L}$ BSA fraction $\mathrm{V}$ and $0.05 \%$ Tyloxapol) and GAST/Fe $(0.3 \mathrm{~g} / \mathrm{L}$ of Bacto Casitone (Difco), $4.0 \mathrm{~g} / \mathrm{L}$ of dibasic potassium phosphate, $2.0 \mathrm{~g} / \mathrm{L}$ of citric acid, $1.0 \mathrm{~g} / \mathrm{L}$ of L-alanine, $1.2 \mathrm{~g} / \mathrm{L}$ of magnesium chloride hexahydrate, $0.6 \mathrm{~g} / \mathrm{L}$ of potassium sulfate, $2.0 \mathrm{~g} / \mathrm{L}$ of ammonium chloride, $1.80 \mathrm{ml} / \mathrm{L}$ of $10 \mathrm{~N}$ sodium hydroxide, $10.0 \mathrm{~mL}$ of glycerol $0.05 \%$ Tween- 80 and $0.05 \mathrm{~g}$ of ferric ammonium citrate adjusted to $\mathrm{pH}$ 6.6).

\section{M. tuberculosis CoaBC knockdown and on-target activity. M. tuberculosis} H37RvMA and its coaBC Tet-OFF conditional knockdown derivative ${ }^{12}$ were grown in Difco Middlebrook 7H9 broth (BD) supplemented with Middlebrook albumin-dextrose-catalase (ADC) enrichment (BD), 0.2\% glycerol (Sigma-Aldrich) and $0.05 \%$ Tween- 80 , unless otherwise indicated. Hygromycin and kanamycin were used at final concentrations of $50 \mu \mathrm{g} / \mathrm{mL}$ and $25 \mu \mathrm{g} / \mathrm{mL}$, respectively, and pantethine (Sigma-Aldrich) supplementation was included at $2.5 \mathrm{mg} / \mathrm{mL}$ where required. The anhydrotetracycline (ATc) inducer was used at concentrations up to $200 \mathrm{ng} / \mathrm{mL}$ in order to transcriptionally silence coaBC in the Tet-OFF hypomorph

The minimum inhibitory concentrations $\left(\mathrm{MIC}_{99}\right.$ ) of the compounds were determined by measuring fluorescence output using Alamar Blue, as previously described (Singh et al. ${ }^{56}$ ). Briefly, 2 -fold serial dilutions of compound were inoculated with a suspension of $M$. tuberculosis at a cell density of $\sim 10^{5} \mathrm{CFU} / \mathrm{mL}$ in a 96-well microtiter plate and incubated at $37^{\circ} \mathrm{C}$ for 10 days, following which $10 \mu \mathrm{L}$ Alamar Blue solution was added and the plates were incubated for a further $24 \mathrm{~h}$. Fluorescence as an indication of growth was measured using a SpectraMax i3x 
Multi-Mode Microplate Reader (Molecular Devices) in bottom-reading mode with excitation at $544 \mathrm{~nm}$ and emission at $590 \mathrm{~nm}$.

Mycobacterium tuberculosis compound uptake. M. tuberculosis $\mathrm{H} 37 \mathrm{Rv}$ was grown to $\mathrm{OD}_{580} 1$ in Middlebrook $7 \mathrm{H} 9$ supplemented with $0.2 \%$ glucose and $0.2 \%$ glycerol. One $\mathrm{mL}$ was added to each nylon Durapore $0.22 \mu \mathrm{m}$ membrane filter. Bacteria-laden filters were placed atop Middlebrook 7H11 agar supplemented with $0.2 \%$ glycerol and $10 \%$ OADC, incubated at $37^{\circ} \mathrm{C}$ for 1 week to expand the biomass, and transferred to lay atop a reservoir containing $7 \mathrm{H} 9$ medium with $0.2 \%$ glucose and $0.2 \%$ glycerol (no tyloxapol) and $10 \mu \mathrm{M}$ of test agent. After $24 \mathrm{~h}$ at $37^{\circ} \mathrm{C}$, bacteria-laden filters were plunged into $1 \mathrm{~mL}$ 40:40:20 methanol:acetonitrile:water pre-cooled to $-20^{\circ} \mathrm{C}$ and lysed in a bead beater while spent media was reserved for extraction and analysis with cell lysates. Both cell lysates and spent media were mixed with equal volumes of $50 \%$ acetonitrile, $0.2 \%$ formic acid for mass spectrometry in positive and negative ion mode as previously described ${ }^{57}$.

Reporting summary. Further information on research design is available in the Nature Research Reporting Summary linked to this article.

\section{Data availability}

Coordinates and structure factors related to this work have been deposited in the PDB with accession numbers: 6TGV, 6TH2 and 6THC. The source data for Tables 1, 2 and Figs. 4, 6 and Supplementary Fig. 7 are provided as a source data file. Other data are available from the corresponding authors upon reasonable request. Source data are provided with this paper.

Received: 9 January 2020; Accepted: 18 November 2020;

Published online: 08 January 2021

\section{References}

1. World Health Organization Global Tuberculosis Report 2019 (World Health Organization, Geneva, 2019).

2. Strauss, E. Coenzyme A biosynthesis and enzymology. in Compreensive Natural Products II Chemistry and Biology, (eds Mander, L. \& Lui, H.-W.) 7, 351-410 (Elsevier Oxford, 2010).

3. Leonardi, R. \& Jackowski, S. Biosynthesis of pantothenic acid and coenzyme A. EcoSal Plus 2 (2007).

4. Tsuchiya, Y. et al. Protein CoAlation and antioxidant function of coenzyme A in prokaryotic cells. Biochem. J. 475, 1909-1937 (2018).

5. Choudhary, C. et al. Lysine acetylation targets protein complexes and coregulates major cellular functions. Science 325, 834-840 (2009).

6. Beld, J., Sonnenschein, E. C., Vickery, C. R., Noel, J. P. \& Burkart, M. D. The phosphopantetheinyl transferases: catalysis of a post-translational modification crucial for life. Nat. Prod. Rep. 31, 61-108 (2014).

7. Wang, M. \& Casey, P. J. Protein prenylation: unique fats make their mark on biology. Nat. Rev. Mol. Cell Biol. 17, 110-122 (2016).

8. Bird, J. G. et al. The mechanism of RNA $5^{\prime}$ capping with NAD+, NADH and desphospho-CoA. Nature 535, 444-447 (2016).

9. Marrakchi, H., Laneelle, M. A. \& Daffe, M. Mycolic acids: structures, biosynthesis, and beyond. Chem. Biol. 21, 67-85 (2014).

10. Guerrini, V. et al. Storage lipid studies in tuberculosis reveal that foam cell biogenesis is disease-specific. PLoS Pathog. 14, el007223 (2018)

11. Peyron, P. et al. Foamy macrophages from tuberculous patients' granulomas constitute a nutrient-rich reservoir for $M$. tuberculosis persistence. PLoS Pathog. 4, e1000204 (2008).

12. Evans, J. C. et al. Validation of $\mathrm{CoaBC}$ as a bactericidal target in the coenzyme a pathway of Mycobacterium tuberculosis. ACS Infect. Dis. 2, 958-968 (2016).

13. Chan, D. S.-H. et al. Structural insights into Escherichia coli phosphopantothenoylcysteine synthetase by native ion mobility-mass spectrometry. Biochem. J. 476, 3125-3139 (2019).

14. Patrone, J. D., Yao, J., Scott, N. E. \& Dotson, G. D. Selective inhibitors of bacterial phosphopantothenoylcysteine synthetase. J. Am. Chem. Soc. 131, 16340-16341 (2009).

15. Kumar, P., Chhibber, M. \& Surolia, A. How pantothenol intervenes in coenzyme-A biosynthesis of Mycobacterium tuberculosis. Biochem. Biophys. Res. Commun. 361, 903-909 (2007).

16. Kupke, T. et al. Molecular characterization of lantibiotic-synthesizing enzyme EpiD reveals a function for bacterial Dfp proteins in coenzyme A biosynthesis. J. Biol. Chem. 275, 31838-31846 (2000).

17. White, M. D. et al. UbiX is a flavin prenyltransferase required for bacterial ubiquinone biosynthesis. Nature 522, 502-506 (2015).

18. Blaesse, M., Kupke, T., Huber, R. \& Steinbacher, S. Crystal structure of the peptidyl-cysteine decarboxylase EpiD complexed with a pentapeptide substrate. EMBO J. 19, 6299-6310 (2000).
19. Blaesse, M., Kupke, T., Huber, R. \& Steinbacher, S. Structure of MrsD, an FAD-binding protein of the HFCD family. Acta Crystallogr. D Biol. Crystallogr. 59, 1414-1421 (2003).

20. Albert, A. et al. The X-ray structure of the FMN-binding protein AtHal3 provides the structural basis for the activity of a regulatory subunit involved in signal transduction. Structure 8, 961-969 (2000).

21. Manoj, N. \& Ealick, S. E. Unusual space-group pseudosymmetry in crystals of human phosphopantothenoylcysteine decarboxylase. Acta Crystallogr. D Biol. Crystallogr. 59, 1762-1766 (2003).

22. Steinbacher, S. et al. Crystal structure of the plant PPC decarboxylase AtHAL3a complexed with an ene-thiol reaction intermediate. J. Mol. Biol. 327, 193-202 (2003).

23. Stanitzek, S., Augustin, M. A., Huber, R., Kupke, T. \& Steinbacher, S. Structural basis of CTP-dependent peptide bond formation in coenzyme A biosynthesis catalyzed by Escherichia coli PPC synthetase. Structure 12, 1977-1988 (2004).

24. Manoj, N., Strauss, E., Begley, T. P. \& Ealick, S. E. Structure of human phosphopantothenoylcysteine synthetase at 2.3 A resolution. Structure 11, 927-936 (2003)

25. Zheng, P. et al. Crystallographic analysis of the catalytic mechanism of phosphopantothenoylcysteine synthetase from Saccharomyces cerevisiae. J. Mol. Biol. 431, 764-776 (2019).

26. Kupke, T. Molecular characterization of the $4^{\prime}$-phosphopantothenoylcysteine synthetase domain of bacterial dfp flavoproteins. J. Biol. Chem. 277, 36137-36145 (2002).

27. Strauss, E., Kinsland, C., Ge, Y., McLafferty, F. W. \& Begley, T. P. Phosphopantothenoylcysteine synthetase from Escherichia coli. Identification and characterization of the last unidentified coenzyme A biosynthetic enzyme in bacteria. J. Biol. Chem. 276, 13513-13516 (2001).

28. Awasthy, D. et al. Essentiality and functional analysis of type I and type III pantothenate kinases of Mycobacterium tuberculosis. Microbiology 156, 2691-2701 (2010).

29. Song, W. J. \& Jackowski, S. Kinetics and regulation of pantothenate kinase from Escherichia coli. J. Biol. Chem. 269, 27051-27058 (1994).

30. Vallari, D. S., Jackowski, S. \& Rock, C. O. Regulation of pantothenate kinase by coenzyme A and its thioesters. J. Biol. Chem. 262, 2468-2471 (1987).

31. Wubben, T. J. \& Mesecar, A. D. Kinetic, thermodynamic, and structural insight into the mechanism of phosphopantetheine adenylyltransferase from Mycobacterium tuberculosis. J. Mol. Biol. 404, 202-219 (2010).

32. Miller, J. R. et al. Phosphopantetheine adenylyltransferase from Escherichia coli: investigation of the kinetic mechanism and role in regulation of coenzyme A biosynthesis. J. Bacteriol. 189, 8196-8205 (2007).

33. Bennett, B. D. et al. Absolute metabolite concentrations and implied enzyme active site occupancy in Escherichia coli. Nat. Chem. Biol. 5, 593-599 (2009).

34. Moolman, W. J., de Villiers, M. \& Strauss, E. Recent advances in targeting coenzyme A biosynthesis and utilization for antimicrobial drug development. Biochem. Soc. Trans. 42, 1080-1086 (2014).

35. Kupke, T. Active-site residues and amino acid specificity of the bacterial $4^{\prime}$-phosphopantothenoylcysteine synthetase CoaB. Eur. J. Biochem. 271, 163-172 (2004).

36. Chakraborty, S., Gruber, T., Barry, C. E. 3rd, Boshoff, H. I. \& Rhee, K. Y. Paraaminosalicylic acid acts as an alternative substrate of folate metabolism in Mycobacterium tuberculosis. Science 339, 88-91 (2013).

37. Warrier, T. et al. N-methylation of a bactericidal compound as a resistance mechanism in Mycobacterium tuberculosis. Proc. Natl Acad. Sci. USA 113, E4523-E4530 (2016).

38. Jansen, R. S. \& Rhee, K. Y. Emerging approaches to tuberculosis drug development: at home in the metabolome. Trends Pharm. Sci. 38, 393-405 (2017).

39. Awasthi, D. \& Freundlich, J. S. Antimycobacterial metabolism: illuminating Mycobacterium tuberculosis biology and drug discovery. Trends Microbiol. 25, 756-767 (2017)

40. Spry, C., Kirk, K. \& Saliba, K. J. Coenzyme A biosynthesis: an antimicrobial drug target. FEMS Microbiol. Rev. 32, 56-106 (2008).

41. Olzhausen, J., Moritz, T., Neetz, T. \& Schuller, H. J. Molecular characterization of the heteromeric coenzyme A-synthesizing protein complex (CoA-SPC) in the yeast Saccharomyces cerevisiae. FEMS Yeast Res. 13, 565-573 (2013).

42. Ruiz, A. et al. Moonlighting proteins Hal3 and Vhs3 form a heteromeric PPCDC with Ykl088w in yeast CoA biosynthesis. Nat. Chem. Biol. 5, 920-928 (2009).

43. Yun, M. et al. Structural basis for the feedback regulation of Escherichia coli pantothenate kinase by coenzyme A. J. Biol. Chem. 275, 28093-28099 (2000).

44. Hartl, J., Kiefer, P., Meyer, F. \& Vorholt, J. A. Longevity of major coenzymes allows minimal de novo synthesis in microorganisms. Nat. Microbiol. 2, 17073 (2017). 
45. Nguyen, L. \& Pieters, J. Mycobacterial subversion of chemotherapeutic reagents and host defense tactics: challenges in tuberculosis drug development. Annu. Rev. Pharm. Toxicol. 49, 427-453 (2009).

46. Peranen, J., Rikkonen, M., Hyvonen, M. \& Kaariainen, L. T7 vectors with modified T7lac promoter for expression of proteins in Escherichia coli. Anal. Biochem. 236, 371-373 (1996).

47. Vonrhein, C. et al. Data processing and analysis with the autoPROC toolbox. Acta Crystallogr. D Biol. Crystallogr. 67, 293-302 (2011).

48. Kabsch, W. XDS. Acta Crystallogr. D Biol. Crystallogr. 66, 125-132 (2010).

49. Evans, P. R. \& Murshudov, G. N. How good are my data and what is the resolution? Acta Crystallogr. D Biol. Crystallogr. 69, 1204-1214 (2013).

50. French, S. \& Wilson, K. Treatment of negative intensity observations. Acta Crystallogr. Sect. A 34, 517-525 (1978).

51. Winn, M. D. et al. Overview of the CCP4 suite and current developments. Acta Crystallogr. D Biol. Crystallogr. 67, 235-242 (2011).

52. McCoy, A. J. et al. Phaser crystallographic software. J. Appl. Crystallogr. 40, 658-674 (2007).

53. Adams, P. D. et al. PHENIX: a comprehensive Python-based system for macromolecular structure solution. Acta Crystallogr. D Biol. Crystallogr. 66 213-221 (2010).

54. Emsley, P., Lohkamp, B., Scott, W. G. \& Cowtan, K. Features and development of Coot. Acta Crystallogr. D. Biol. Crystallogr. 66, 486-501 (2010).

55. Jubb, H. C. et al. Arpeggio: a web server for calculating and visualising interatomic interactions in protein structures. J. Mol. Biol. 429, 365-371 (2017).

56. Singh, V. et al. The complex mechanism of antimycobacterial action of 5fluorouracil. Chem. Biol. 22, 63-75 (2015).

57. Nandakumar, M., Prosser, G. A., de Carvalho, L. P. \& Rhee, K. Metabolomics of Mycobacterium tuberculosis. Methods Mol. Biol. 1285, 105-115 (2015).

\section{Acknowledgements}

We dedicate this work to the memory of Professor Chris Abell who sadly died suddenly on Monday 26th October at the age of 62. Chris developed highly interdisciplinary research focused on understanding the mechanisms of key enzymes and the development of chemistry for structure-guided fragment-based drug discovery. He leaves a lasting legacy through his work and the numerous scientists whose careers he helped to shape. This work was funded by the Bill and Melinda Gates Foundation HIT-TB (OPP1024021) and SHORTEN-TB (OPP1158806) (VMendes, JCE and MB) and in part by the Intramural Research Program of NIH, NIAID (HIMB and CEB) and the South African Medical Research Council and National Research Foundation (VMizrahi). J.H. was financially supported by Swiss National Science Foundation (SNSF Early PostDoc. Mobility fellowship, P2ZHP2_164947) and the Marie Curie Research Grants Scheme, EU H2020 Framework Programme (H2020-MSCA-IF-2017, ID: 789607). C.S. was funded in part by a NHMRC Overseas Biomedical Fellowship (1016357) and in part by the Bill and Melinda Gates Foundation HIT-TB (OPP1024021). CoaBC screening was funded by a MRC-CinC (grant no. MC_PC_14099). T.L.B. is funded by the Wellcome Trust (Wellcome Trust Investigator Award 200814_Z_16_Z: RG83114). The authors would like to thank the Diamond Light Source for beam-time (proposals mx9537, mx14043, mx18548), the Seattle Structural Genomics Centre for Infectious Disease for kindly providing the M. smegmatis CoaB plasmid and Dr. Nuno Empadinhas for graciously providing the DNA of $M$. smegmatis $\mathrm{mc}^{2} 155$.

\section{Author contributions}

V.Mendes wrote the manuscript. V.Mendes designed and performed all the crystallographic experiments with the help of M.B., O.B. and J.C.W. V.Mendes and J.H. designed and performed the kinetic experiments. J.H. synthesised 4 '-phosphopantothenate. P.H.M.T. performed docking experiments. D.S.C. performed the native mass spectrometry experiments. S.G., T.B., S.O'N., S.D., J.P. and C.S. developed and performed the high-throughput screening. J.C.E., S.L.L. and H.I.M.B. performed the microbiology experiments on M. tuberculosis H37Rv. Z.W. and N.N. performed the compound uptake experiments. V.Mendes, J.C.E., S.G., A.G.C., P.C.R., K.Y.R., C.A., H.I.M.B., C.E.B., V.Mizrahi, P.G.W. and T.L.B. managed the project. All authors approved the manuscript.

\section{Competing interests}

The authors declare no competing interests.

\section{Additional information}

Supplementary information is available for this paper at https://doi.org/10.1038/s41467020-20224-x.

Correspondence and requests for materials should be addressed to V.M. or T.L.B.

Peer review information Nature Communications thanks Mickaël Blaise, Hao Wang and the other, anonymous, reviewer(s) for their contribution to the peer review of this work. Peer reviewer reports are available.

Reprints and permission information is available at http://www.nature.com/reprints

Publisher's note Springer Nature remains neutral with regard to jurisdictional claims in published maps and institutional affiliations.

Open Access This article is licensed under a Creative Commons Attribution 4.0 International License, which permits use, sharing, adaptation, distribution and reproduction in any medium or format, as long as you give appropriate credit to the original author(s) and the source, provide a link to the Creative Commons license, and indicate if changes were made. The images or other third party material in this article are included in the article's Creative Commons license, unless indicated otherwise in a credit line to the material. If material is not included in the article's Creative Commons license and your intended use is not permitted by statutory regulation or exceeds the permitted use, you will need to obtain permission directly from the copyright holder. To view a copy of this license, visit http://creativecommons.org/ licenses/by/4.0/.

(C) The Author(s) 2021 